\title{
Immunity
}

\section{Ribosome-Targeting Antibiotics Impair T Cell Effector Function and Ameliorate Autoimmunity by Blocking Mitochondrial Protein Synthesis}

\section{Graphical Abstract}

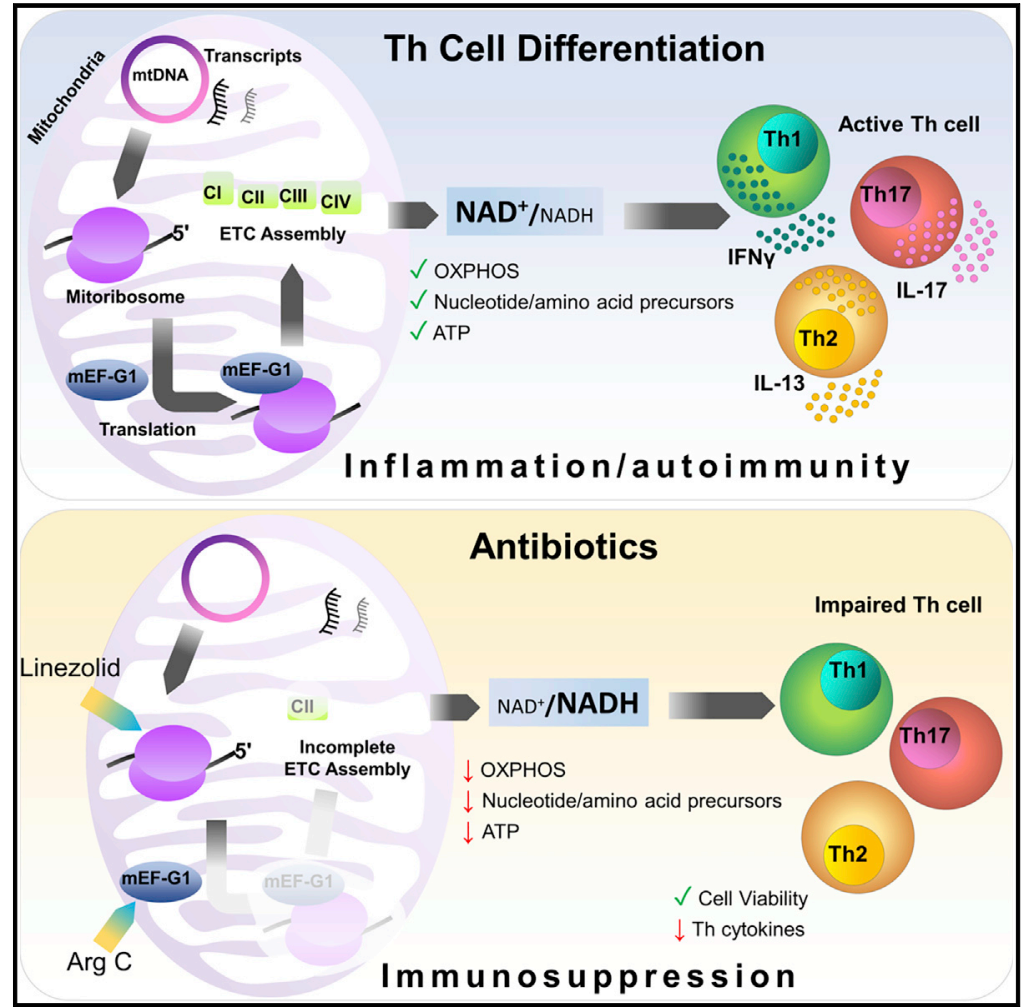

\section{Highlights}

- Linezolid impairs T cell cytokine production by interfering with mitochondria

- Mitochondrial translation is necessary for T cell function and pathology

- Intracellular NAD ${ }^{+}$and NADH levels are coupled to Th17 cytokine production

- The cyclic peptide Argyrin C shows potential as an immunosuppressive drug

\section{Authors}

Luís Almeida, Ayesha Dhillon-LaBrooy, Carla N. Castro, ..., Rolf Müller, Luís F. Moita, Tim Sparwasser

\section{Correspondence}

sparwasser.office@uni-mainz.de

\section{In Brief}

Linezolid is well characterized as an antibiotic, but its effects on host cells are less understood. Almeida et al. show that Linezolid suppresses autoimmunity by interfering with $\mathrm{T}$ cell function. By inhibiting mitochondrial translation, it introduces metabolic changes in differentiating $T$ cells, disrupting their redox balance and impairing cytokine production. 


\title{
Ribosome-Targeting Antibiotics Impair T Cell Effector Function and Ameliorate Autoimmunity by Blocking Mitochondrial Protein Synthesis
}

\author{
Luís Almeida, ${ }^{1,2,15}$ Ayesha Dhillon-LaBrooy, ${ }^{1,2,15}$ Carla N. Castro, ${ }^{1}$ Nigatu Adossa, ${ }^{4,5}$ Guilhermina M. Carriche, ${ }^{1,2}$ \\ Melanie Guderian, ${ }^{1}$ Saskia Lippens, ${ }^{6}$ Sven Dennerlein, ${ }^{7}$ Christina Hesse, ${ }^{3}$ Bart N. Lambrecht, ${ }^{8}$ Luciana Berod, ${ }^{1,9}$ \\ Leif Schauser, ${ }^{4}$ Bruce R. Blazar, ${ }^{10}$ Markus Kalesse, ${ }^{11,12}$ Rolf Müller, ${ }^{13}$ Luís F. Moita, ${ }^{14}$ and Tim Sparwasser ${ }^{1,2,16, *}$ \\ ${ }^{1}$ Institute of Infection Immunology, TWINCORE, Center for Experimental and Clinical Infection Research, Hannover Medical School and the \\ Helmholtz Center for Infection Research, Hannover 30625, Germany \\ 2Institute of Medical Microbiology and Hygiene, University Medical Center of the Johannes Gutenberg-University, Mainz 55131, Germany \\ ${ }^{3}$ Fraunhofer Institute for Toxicology and Experimental Medicine (ITEM), Hannover 30625, Germany \\ ${ }^{4}$ QIAGEN, Aarhus C 8000, Denmark \\ 5 University of Turku, Computational Biomedicine, Turku Center for Biotechnology, Turku 20520, Finland \\ ${ }^{6}$ VIB Imaging Core Facility Gent, Gent 9052, Belgium \\ ${ }^{7}$ Department of Cellular Biochemistry, University Medical Center, Göttingen 37073, Germany \\ ${ }^{8}$ VIB-UGent, Center for Inflammation Research, Gent 9052, Belgium \\ Institute of Molecular Medicine, University Medical Center of the Johannes Gutenberg-University Mainz, Mainz, Germany \\ ${ }^{10}$ Department of Pediatrics, Division of Blood and Marrow Transplantation, University of Minnesota, Minneapolis, MN 55454, USA \\ ${ }^{11}$ Institute for Organic Chemistry, Leibniz University Hannover, Hannover, Germany \\ ${ }^{12} \mathrm{Helmholtz}$ Center for Infection Research (HZI), Braunschweig 38124, Germany \\ ${ }^{13}$ Helmholtz Institute for Pharmaceutical Research, Helmholtz Center for Infection Research and Department of Pharmaceutical \\ Biotechnology, Saarland University, Saarbrücken 66123, Germany \\ ${ }^{14}$ Innate Immunity and Inflammation Laboratory, Instituto Gulbenkian de Ciência, Oeiras, Portugal \\ ${ }^{15}$ These authors contributed equally \\ ${ }^{16}$ Lead Contact \\ *Correspondence: sparwasser.office@uni-mainz.de \\ https://doi.org/10.1016/j.immuni.2020.11.001
}

\section{SUMMARY}

While antibiotics are intended to specifically target bacteria, most are known to affect host cell physiology. In addition, some antibiotic classes are reported as immunosuppressive for reasons that remain unclear. Here, we show that Linezolid, a ribosomal-targeting antibiotic (RAbo), effectively blocked the course of a T cellmediated autoimmune disease. Linezolid and other RAbos were strong inhibitors of T helper-17 cell effector function in vitro, showing that this effect was independent of their antibiotic activity. Perturbing mitochondrial translation in differentiating T cells, either with RAbos or through the inhibition of mitochondrial elongation factor G1 (mEF-G1) progressively compromised the integrity of the electron transport chain. Ultimately, this led to deficient oxidative phosphorylation, diminishing nicotinamide adenine dinucleotide concentrations and impairing cytokine production in differentiating T cells. In accordance, mice lacking mEF-G1 in T cells were protected from experimental autoimmune encephalomyelitis, demonstrating that this pathway is crucial in maintaining $T$ cell function and pathogenicity.

\section{INTRODUCTION}

Bacteria require intact cell walls and functional ribosomes to retain their structural and metabolic integrity. As such, inhibition of these processes by antibiotics either kills bacteria or prevents their growth and division (Kohanski et al., 2010; Silhavy et al., 2010; Wilson and Doudna Cate, 2012). As eukaryotic cells do not possess cell walls and their ribosomes are structurally different from bacterial ribosomes, antibiotics can be used to eradicate bacterial infections with limited toxicity to the host. Nevertheless, some antibiotics have reported side effects, such as candidiasis, anemia, bone marrow suppression, lactic acidosis, and immunosuppression (Hellinger and Brewer, 1999; Josefsdottir et al., 2017; Mao et al., 2018; Ónodi-Nagy et al., 2015; Prieto de Paula et al., 2017; Tedesco, 1975; Xu et al., 2008; Zimmermann et al., 2018). Since antibiotics are often administered to stave off infections, it is important to understand the mechanisms governing antibiotic-mediated immunosuppression. Without a proper immune response, both the clearance of infections and control of opportunistic pathogens are impaired. Here, we focused on Linezolid, a ribosomal-targeting antibiotic (RAbo) from the Oxazolidinone family, which targets 
Gram-positive bacteria (Perry and Jarvis, 2001) and is approved (and reserved) for the treatment of several multi-resistant bacterial infections (Hashemian et al., 2018). Patients requiring Linezolid treatment often present in a critical state and are at increased risk of fungal infections (Falagas and Vardakas, 2008). Moreover, Linezolid is associated with higher mortality by Gram-negative pathogens when compared with Vancomycin. As both antibiotics share a similar spectrum of action (Wilcox et al., 2009), this discrepancy is unusual.

Linezolid, like other RAbos, inhibits mitochondrial translation in mammalian systems and cell lines by occupying the peptidyl transferase center of the mitochondrial ribosome (mitoribosome), interfering with the binding of aminoacyl-tRNAs (Leach et al., 2007; McKee et al., 2006; Moullan et al., 2015; Zhang et al., 2005). The assembly of electron transport chain (ETC) complexes requires the coordinated translation of proteins by cytosolic and mitochondrial ribosomes (Priesnitz and Becker, 2018; Richter-Dennerlein et al., 2016). By blocking mitoribosomes, RAbos lead to an imbalance of nuclear and mitochondrial-encoded ETC subunits (Houtkooper et al., 2013). This mitonuclear imbalance and its relevance to organismal physiology have been previously explored in different fields of medical research. Specifically, inhibition of mitochondrial translation reduces adipokine secretion in adipocytes (Llobet et al., 2017), improves worm lifespan in C. elegans (Houtkooper et al., 2013), and selectively kills leukemia cells (Skrtić et al., 2011). The consequence of blocking mitochondrial protein synthesis in immune cells, however, has not been well elucidated.

Here, we show that Linezolid exhibits immunosuppressive properties, preventing the development of self-reactive $\mathrm{T}$ helper (Th) cells in a mouse model of multiple sclerosis. Linezolid and other RAbos also inhibited Th17 cell function in vitro, showing that immunosuppression occurred independently of their antibiotic activity. Mechanistically, we demonstrate that inhibiting mitochondrial translation led to a mitonuclear imbalance in differentiating Th17 cells, impairing mitochondrial activity and interleukin-17 (IL-17) production. In conclusion, administration of RAbos should be carried out with extra caution to prevent undesired immunosuppression. On the other hand, repurposing of RAbos and/or development of novel drugs with a similar mechanism of action could potentially be used to control T cell-mediated autoimmune disorders.

\section{RESULTS}

\section{Linezolid Inhibits the Onset of a T Cell-Mediated} Autoimmune Disease

To determine if Th cell responses in vivo were altered by RAbos treatment, we employed the murine model of $\mathrm{T}$ cell-mediated autoimmunity experimental autoimmune encephalomyelitis (EAE). Myelin oligodendrocyte glycoprotein (MOG)-immunized mice developed classical clinical signs of EAE, presenting with infiltrating Th cells in the central nervous system (CNS), as well as decreased motility. Administration of a human-equivalent dose of Linezolid limited the development and severity of EAE symptoms (Figures $1 \mathrm{~A}$ and $1 \mathrm{~B})$. This correlated with lower frequency and numbers of MOG-specific IL-17- and interferon- $\gamma$ (IFN- $\gamma$ )-producing Th cells in the CNS of Linezolid-treated mice (Figure 1C); the frequency of FoxP3 ${ }^{+}$Th cells was not affected.
Antibiotics can disturb the intestinal microbiome, which in turn can influence the outcome of an immune response (Hagan et al., 2019; Mestre et al., 2019; Ochoa-Reparaz et al., 2009). To rule out that any effects mediated by Linezolid were due to its antibacterial activity, Vancomycin, which holds a similar spectrum of bacterial activity as Linezolid (Mutnick et al., 2002), was used as control. Of note, while Vancomycin inhibits cell wall synthesis in bacterial cells, Linezolid inhibits prokaryotic ribosomes (Gardete and Tomasz, 2014; Leach et al., 2007). Vancomycintreated mice developed severe EAE symptoms comparable to those of the untreated group, suggesting that Linezolid's immunosuppression was due to its effect on host, and not bacterial, cells.

\section{Mitochondrial Translation Inhibition by Antibiotics Inhibits Th17 Cell Function}

Because mitochondria are of prokaryotic origin, there are similarities between the bacterial and mitochondrial protein translation machineries (Degli Esposti et al., 2014); consequently, some RAbos can also inhibit mitoribosomes. This is true not only for Linezolid but also for other antibiotics from different classes such as Tigecycline and Thiamphenicol (Jager and Bass, 1975; Lamb et al., 2015; Yunis et al., 1973). Hence, we postulated that RAbos inhibited Th17 cell function through inhibition of mitochondrial translation. In accordance, when murine naive $\mathrm{CD}^{+} \mathrm{T}$ cells were cultured under Th17 cell-polarizing conditions in the presence of the aforementioned antibiotics, IL-17 production was reduced in a dose-dependent manner (Figure $2 \mathrm{~A}$, above). Loss of cytokine-producing cells was not caused by death of effector cells, as viability was unaffected (Figure 2A, below). To verify that this effect was not exclusive to murine cells, we differentiated human cord blood-derived naive T cells under Th17 cell-polarizing conditions in the presence of Linezolid. Accordingly, human Th17 cells equally presented lower IL-17 secretion (and normal viability) upon Linezolid treatment (Figure $2 \mathrm{~B}$ ). We then sought to confirm that Linezolid was able to acutely inhibit mitochondrial translation in T cells. To this end, we labeled mitochondrial translation products with [ $\left[{ }^{35} \mathrm{~S}\right]-$ methionine in a murine lymphoma $T$ cell line (EL-4), pretreated for $1 \mathrm{~h}$ with $100 \mu \mathrm{M}$ of Linezolid. We observed a near-complete blockage of $\left[{ }^{35} \mathrm{~S}\right]$-methionine incorporation into mitochondrialencoded ETC subunits (Figure 2C), which coincided with the concentration required to fully inhibit $\mathrm{IL}-17$ production (Figure 2A).

The ETC is composed of five complexes, made up of several protein subunits that must be correctly assembled. While all complex II subunits are encoded in the nucleic DNA (nDNA) and translated in the cytosol, complexes I, III, IV, and V contain subunits encoded by both nDNA and mitochondrial DNA (mtDNA). Therefore, the assembly of these complexes requires a tight coordination between the cytosolic and mitochondrial protein machinery. When mitochondrial translation is interrupted, a mitonuclear imbalance occurs, characterized by a higher ratio of nDNA- to mtDNA-encoded subunits (Houtkooper et al., 2013; Moullan et al., 2015). Accordingly, Linezolid selectively depleted the mtDNA-encoded mitochondrial-NADH-ubiquinone oxidoreductase chain 1 (ND1) and cytochrome C oxidase I (COX1) proteins in Th17 cells (Figure 2D). In contrast, the quantity of nuclear-encoded succinate dehydrogenase complex 
A

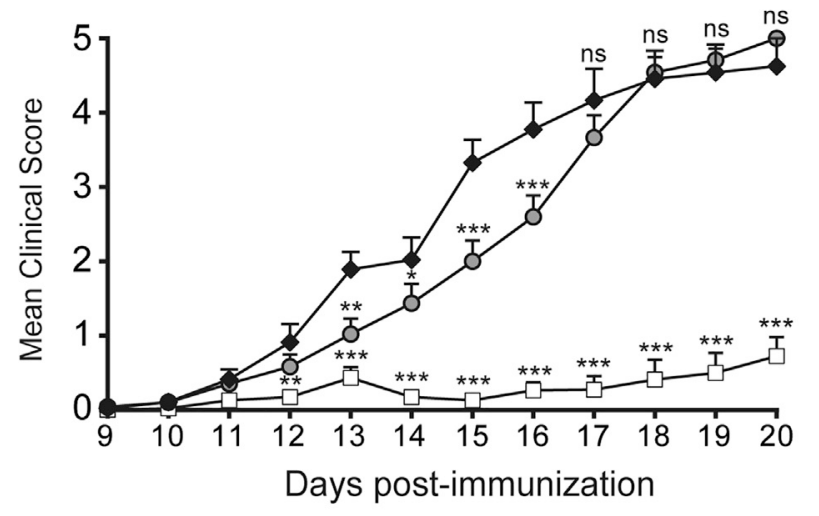

$\bullet$ Untreated

- - Linezolid

- Vancomycin
B

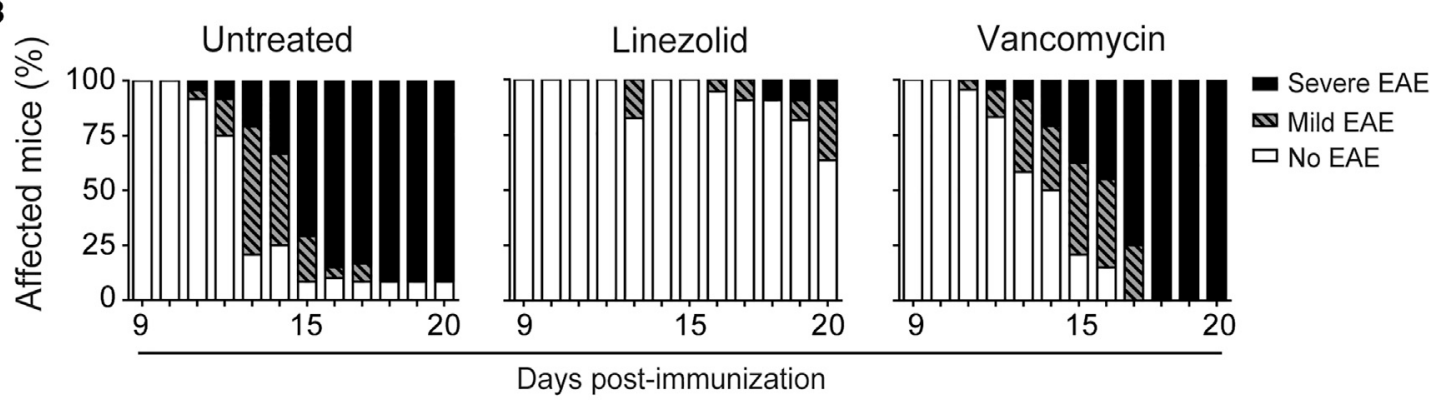

C

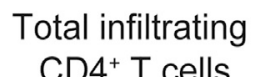

MOG-specific IL- $17^{+} \mathrm{CD} 4^{+} \mathrm{T}$ cells IFN- $\mathrm{\gamma}^{+} \mathrm{CD} 4^{+} \mathrm{T}$ cells
Foxp3 $^{+}$

CD4 ${ }^{+} \mathrm{T}$ cells
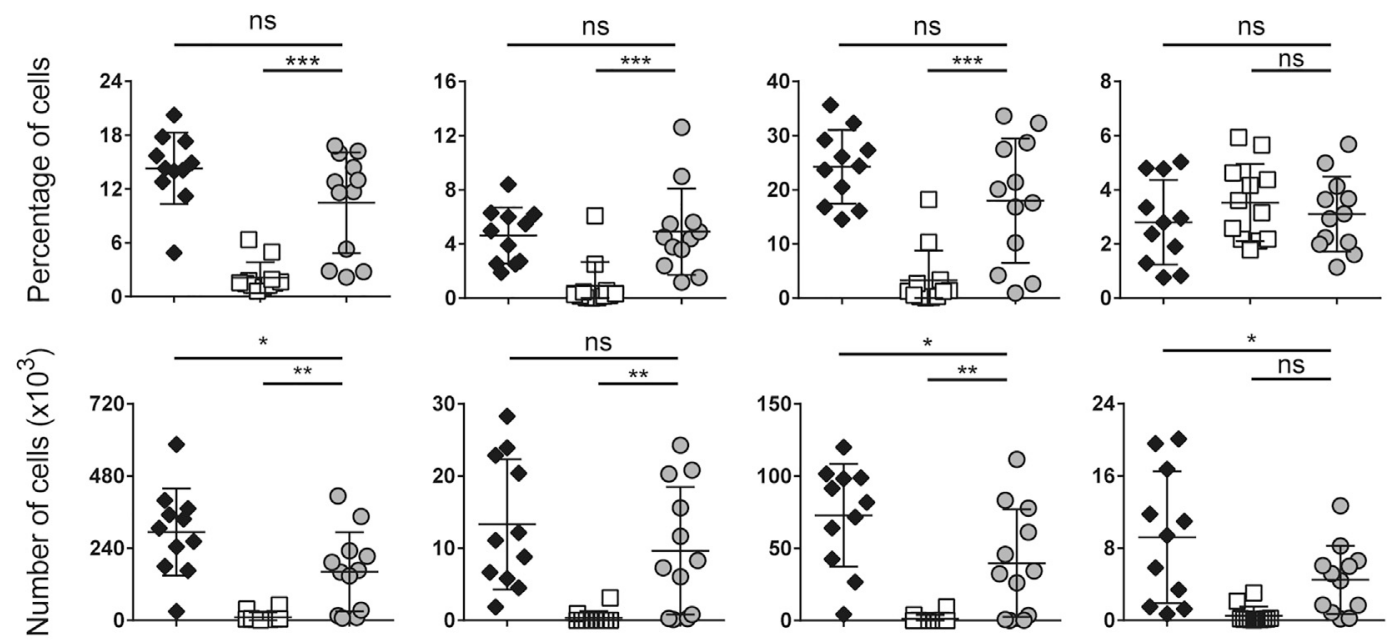

\section{$\checkmark$ Untreated $\quad$ Linezolid O Vancomycin}

Figure 1. Linezolid Inhibits the Onset of T Cell-Mediated Autoimmune Diseases EAE in MOG-Immunized Mice (A) EAE clinical score of mice treated daily with Linezolid, Vancomycin, or untreated.

(B) Distribution of disease severity: no EAE: score $<1$, mild EAE: $1 \leq$ score $<3$, severe EAE: score $\geq 3$.

(C) Frequency (top) and number (bottom) of CD4 ${ }^{+} \mathrm{T}$ cells isolated from the central nervous system of Linezolid-treated, Vancomycin-treated, and untreated mice. Plots are obtained from the pooled data of three independent experiments.

(A-C) individual experiments, with error bars showing the SEM of the pooled scores (A). Statistical significance was determined using two-way ANOVA with Bonferroni multiple corrections test compared to untreated mice. ${ }^{*} p<0.05,{ }^{* *} p<0.01$, and ${ }^{* \star *} p<0.001$. 
A
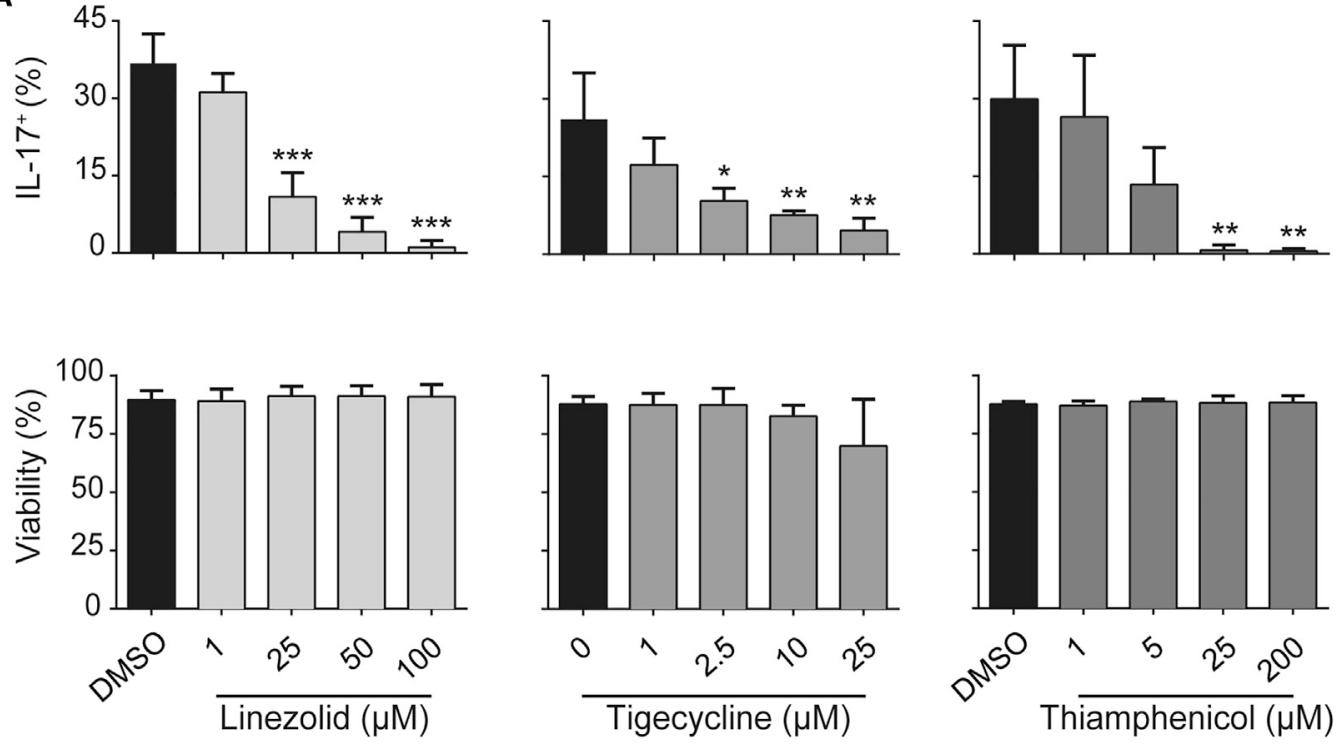

B
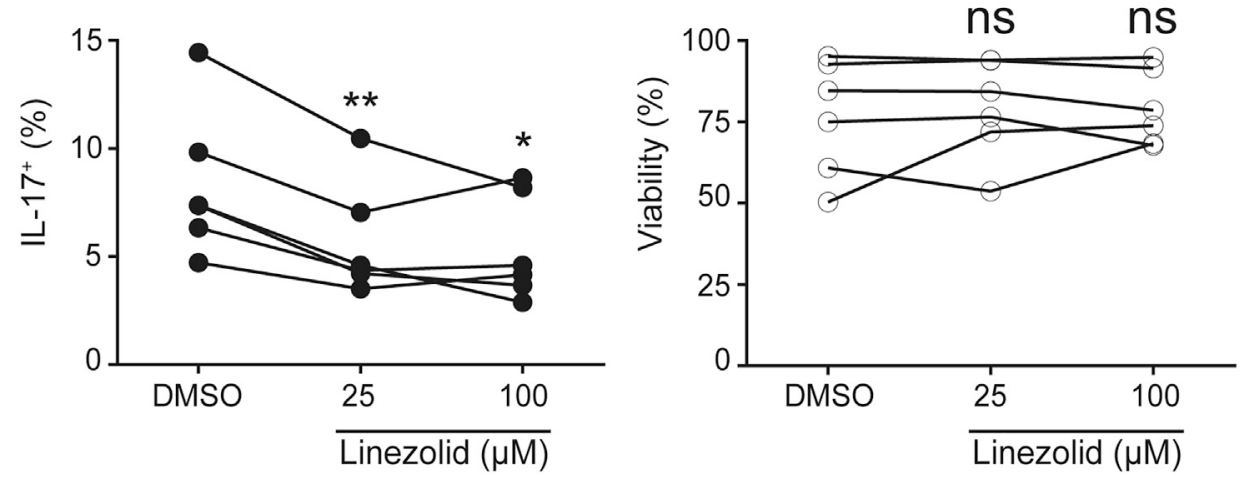

C

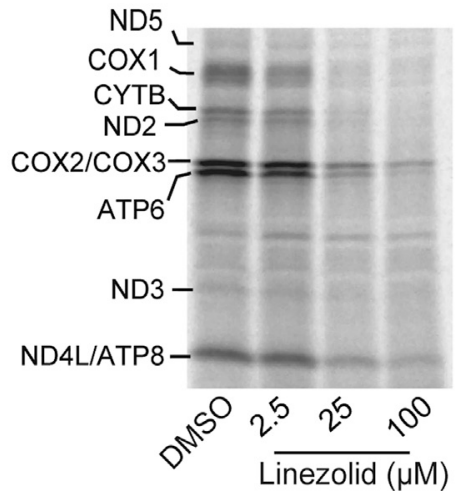

D

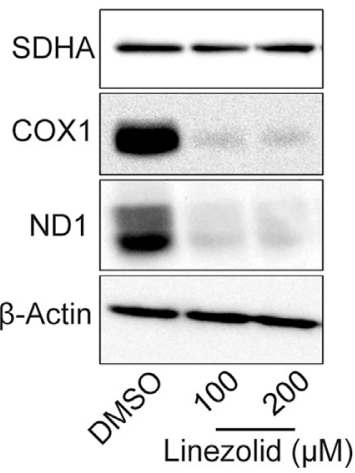

E

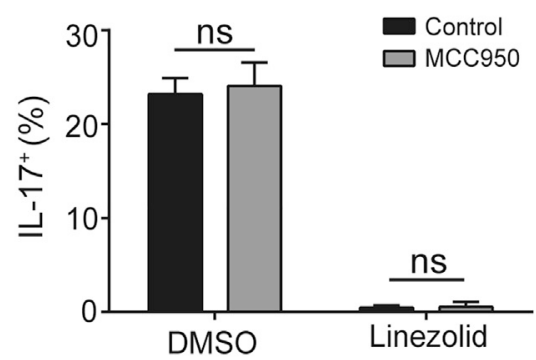

Figure 2. Linezolid and Other RAbos Disrupt Th17 Effector Cell Function by Targeting Mitochondrial Translation (A) Naive mouse $\mathrm{CD}^{+} \mathrm{T}$ cells cultured under Th17 cell polarizing conditions with Linezolid, Tigecycline, or Thiamphenicol. After $96 \mathrm{~h}$ of culture, cells were stained for intracellular IL-17. Bar graphs represent $\%$ of IL-17 $7^{+}$cells amongst live $\mathrm{CD} 4^{+} \mathrm{T}$ cells (top) and $\%$ viable $\mathrm{CD} 4^{+} \mathrm{T}$ cells (bottom).

(B) Human naive T cells were stained for intracellular IL-17 (right) after being differentiated for 6 days in the presence of the indicated concentrations of Linezolid. Graphs contain the data for each of six individual donors, indicated by connected dots: $\%$ of IL-1 $17^{+}$cells amongst live $\mathrm{CD} 4^{+} \mathrm{T}$ cells (left) and $\%$ of viable CD4 ${ }^{+} \mathrm{T}$ cells (right). 
flavoprotein subunit $A(S D H A)$ was not affected (Figure 2D). We further confirmed that Linezolid also inhibited COX1 expression in $\mathrm{CD}^{+} \mathrm{T}$ cells in vivo during EAE (Figure S1A), while not markedly affecting $\mathrm{CD}^{+} \mathrm{T}$ cell proliferation, measured by bromodeoxyuridine (BrdU) incorporation (Figure S1B). Linezolid is a reported activator of the NLRP3 inflammasome; however, the NLRP3 inhibitor MCC950 did not prevent Linezolid from inhibiting IL-17 production (Figure 2E). These findings confirm that mitoribosomes-but not cytosolic ribosomes - are targets of Linezolid and necessary for IL-17 production in Th17 cells.

\section{Argyrin C and Linezolid Exert Analogous Effects on Differentiating Th17 Cells}

Mitoribosomes contain 12S and 16S ribosomal RNA (rRNA), encoded by the MT-RNR1 and MT-RNR2 genes, respectively. These rRNAs differ among individuals depending on their mitochondrial haplotype (Chen et al., 2012; Häkli et al., 2015; Pacheu-Grau et al., 2010). This has the potential to modulate the susceptibility of mitoribosomes to Linezolid (Pacheu-Grau et al., 2013). Furthermore, as Linezolid is a reserve antibiotic, it is difficult to conceive it as an immunosuppressant. To explore different ways of inhibiting mitochondrial translation, we employed the Argyrin (Arg) family of compounds (Figures $3 \mathrm{~A}$ and $\mathrm{S} 2 \mathrm{~A}$ ). Args do not bind to the mitoribosome but instead to mitochondrial elongation factor G1 (mEF-G1) (Nyfeler et al., 2012), an enzyme necessary for the elongation step of mitochondrial protein synthesis (Tsuboi et al., 2009). The inhibitory capacities of the different Args were quantified in murine naive $\mathrm{CD} 4^{+} \mathrm{T}$ cells under Th17 cell polarizing conditions (Figures S2A and S2B). Args $A$ and $B$ reduced the frequency of IL-17-producing $T$ cells only at the highest concentration (240 nM) tested, while Args C and $D$ were effective at much lower doses (24 nM). Notably, Args $\mathrm{F}$ and $\mathrm{H}$ had no immunosuppressive activity at the tested concentrations (Figure S2B, left). Nevertheless, Arg F still retained the capacity to inhibit IL-17 production, albeit at higher concentrations (>600 nM) (Figure S2C, left). This is consistent with a previous report, showing that Arg F inhibits COX2 expression at doses higher than $600 \mathrm{nM}$ (Chen et al., 2017). As we observed for RAbos, cellular viability was not affected by any Arg (Figure S2B, right and Figure S2C, right).

Considering the differences in the activity of each compound, we focused on the most active metabolite, Arg C, for further studies (Figure 3A). To assess whether Arg C and Linezolid exert a general inhibitory effect on effector Th cell subset function, we differentiated Th1, Th2, and Th17 cells under a broader range of Arg $\mathrm{C}$ and Linezolid concentrations. IFN $-\gamma$ and IL-13 production by murine Th1 and Th2 cells, respectively, was reduced by both Arg C and Linezolid (Figures S3A-S3D). Similar to Linezolid, Arg $C$ reduced the frequency of human IL-17-producing T cells (Figure 3B, above) without affecting viability (Figure 3B, below). mEF-G1 inhibition hampered mitochondrial translation, measured by a near-complete blockage of $\left[{ }^{35} \mathrm{~S}\right]$-methionine incorporation in mtDNA-encoded subunits in Arg C-treated EL4 cells (Figure $3 \mathrm{C}$ ). A reduction of $\left[{ }^{35} \mathrm{~S}\right]$-methionine incorporation was also detectable after Arg F pretreatment (60 nM). However, this impairment was partial and only observed at a concentration 100-fold higher than that required for a similar inhibition with Arg C. This coincided with the lack of cytokine inhibition by Arg F at $60 \mathrm{nM}$ (Figures S2B and S2C).

Both Linezolid and Arg C present as inhibitors of mitochondrial protein synthesis. Despite the different molecular targets, both inhibited Th17 cell function. To determine overall similarities between the two drugs, we performed RNA sequencing (RNA-seq) analysis on Th17 cells exposed to Linezolid, Arg C, or vehicle for 96 h. Differential gene expression analysis showed that most genes significantly up or downregulated by Linezolid were equally regulated by Arg C (Figure 3D). Glycolysis and Th17 cell activation were among the top pathways downregulated by both drugs (Figures $3 \mathrm{E}$ and $3 \mathrm{~F}$ ). This lower expression of glycolytic genes was not due to lower expression of HIF1 $\alpha$ (Figure S2D) nor was it restored by the HIF1 $\alpha$ activator dimethyloxallyl glycine (DMOG; Figure S2E). Genes downregulated by both Linezolid and Arg C in the "Th17 activation pathway" category included several Th17 cell-associated genes, such as $1 / 17 a$, II17f, II23r, Rorc, Ahr, and II21 (Figure 3F). Of note, pathways significantly upregulated by Linezolid and $\operatorname{Arg} C$ were associated with cell cycle control and response to DNA damage (Figures 3E and $3 F$ ). Overall, our results demonstrate a high degree of similarity between the effects of Linezolid and Arg C on Th17 cells.

\section{Proliferating T Cells Depend on Functional Mitoribosomes to Maintain Their ETC Integrity and Effector Function}

Naive T cells have a lower proliferation rate and cellular respiration and decreased mitochondrial proteome when compared to activated T cells (Almeida et al., 2016; Buck et al., 2016; Liesa and Shirihai, 2016; Ron-Harel et al., 2016). T cell activation leads to several rounds of cell division, which require the biogenesis of mitochondrial proteins, including those encoded by mtDNA. To assess the reliance of differentiating $T$ cells on mitochondrial translation, we measured the intracellular content of ND1 and COX1 throughout a culture with Arg C. After $48 \mathrm{~h}$ of treatment, the amounts of both ND1 and COX1 decreased exclusively in Arg C-treated differentiating Th17 cells. Arg F at $60 \mathrm{nM}$ failed to reduce the expression of either subunit (Figure 4A, left). Like Linezolid, Arg $\mathrm{C}$ did not reduce the expression of the nuclear-encoded protein SDHA. We further hypothesized that non-proliferating naive $T$ cells would lose their ETC subunits slower when mitochondrial translation is inhibited. To test this, we quantified the amount of COX1 and ND1 proteins in IL-7-maintained, Arg C-treated, naive T cells. COX1 and ND1 were still detectable even after $120 \mathrm{~h}$ of Arg C-treatment, showing that activated $T$ cells are more sensitive to inhibition of this pathway than their naive counterparts (Figure $4 \mathrm{~A}$, right). To exclude compensatory

(C) Mitochondrial translation products in EL-4 cells pre-incubated for $1 \mathrm{~h}$ with Linezolid or DMSO and radioactively labeled with [ $\left.{ }^{35} \mathrm{~S}\right]-\mathrm{methionine.}$

(D) SDHA, COX1, ND1, and $\beta$-actin quantified by western blot in mouse Th17 cells after $96 \mathrm{~h}$ of culture.

(E) Naive mouse $\mathrm{CD}^{+} \mathrm{T}$ cells cultured under Th17 cell polarizing conditions in the presence of Linezolid, with and without the NLRP3 inflammasome inhibitor MCC950 (10 $\mu \mathrm{M})$.

Plots are representative of two $(C)$ or three $(D)$ experiments, and bar graphs are pooled means of technical replicates from three (A, middle and right and $E)$ or four (A, left) independent experiments, with error bars representing the SD of the pooled means. ${ }^{*} p<0.05$, ${ }^{* *} p<0.01$, and ${ }^{* * *} p<0.001$. See also Figure $S 1$. 
A

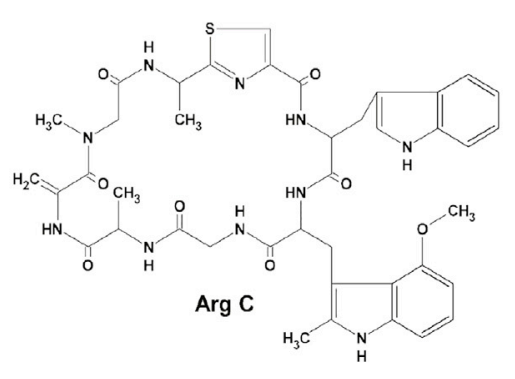

C

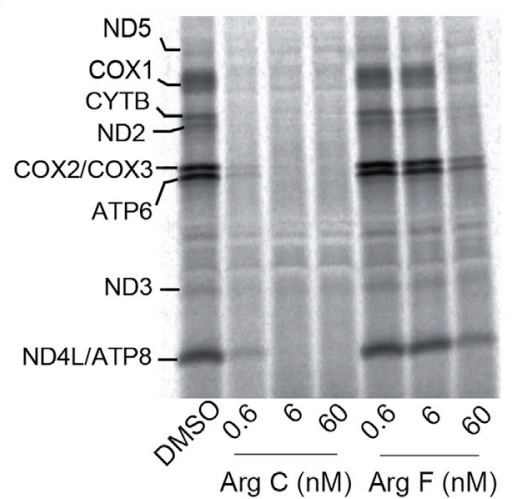

E

Downregulated by $\operatorname{Arg} C$ and Linezolid

\begin{tabular}{|l|c|c|}
\hline \multicolumn{1}{|c|}{ Top canonical pathways } & p-value & Genes \\
\hline Glycolysis I & $7.02 \mathrm{E}-08$ & 10 \\
\hline Hepatic Fibrosis / Hepatic Stellate Cell Activation & $4.04 \mathrm{E}-07$ & 27 \\
\hline Th17 Activation Pathway & $1.27 \mathrm{E}-06$ & 15 \\
\hline T Helper Cell Differentiation & $2.81 \mathrm{E}-05$ & 13 \\
\hline HMGB1 Signalling & $3.33 \mathrm{E}-05$ & 21 \\
\hline
\end{tabular}

$\mathbf{F}$

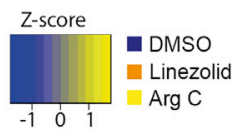

Glycolysis I
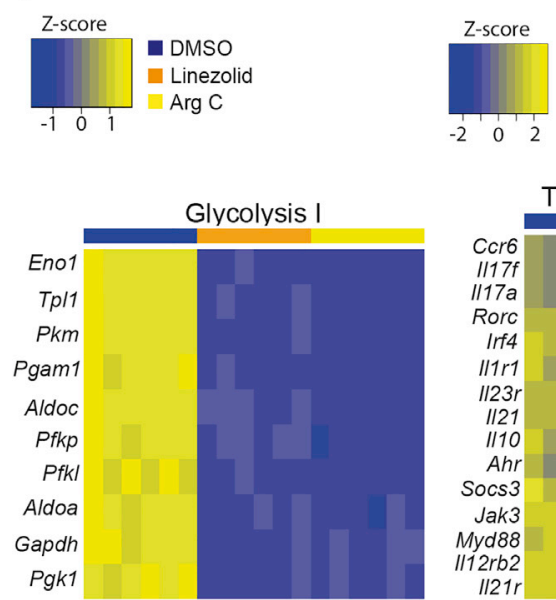

B Murine Th17 cells

Human Th17 cells
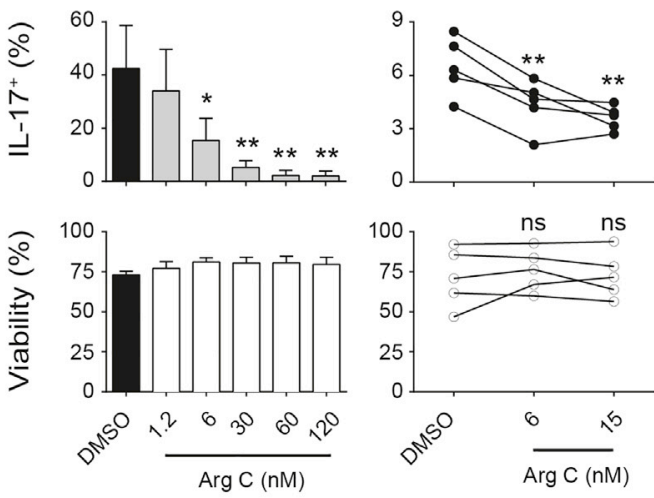

D
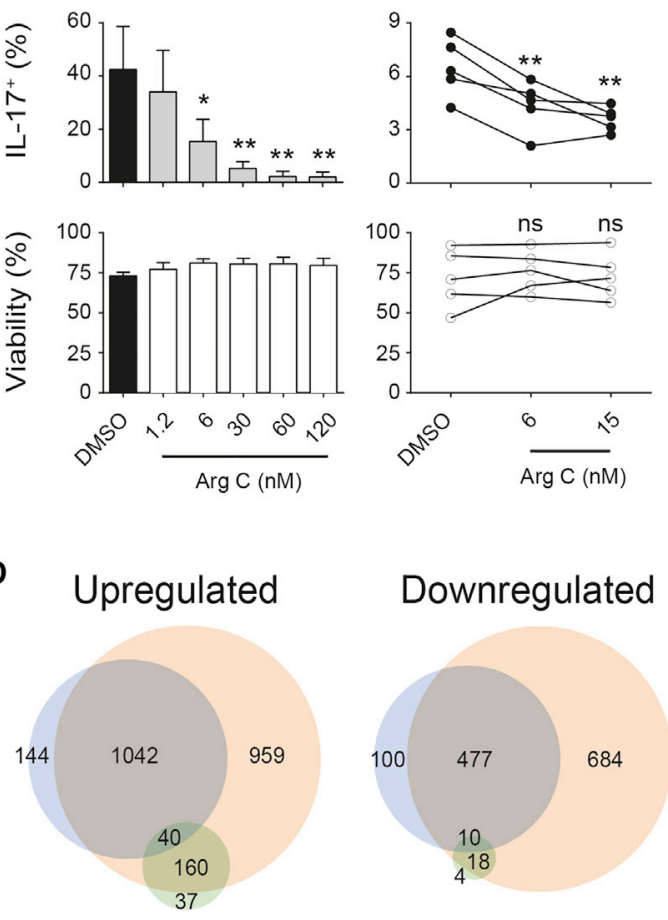

Downregulated

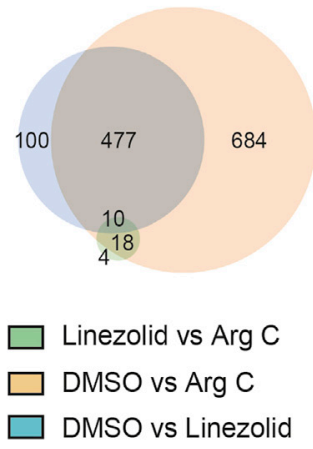

Upregulated by Arg C and Linezolid

\begin{tabular}{|l|c|c|}
\hline \multicolumn{1}{|c|}{ Top canonical pathways } & p-value & Genes \\
\hline Kinetochore Metaphase Signalling Pathway & $5.95 \mathrm{E}-37$ & 38 \\
\hline Cell Cycle Control of Chromosomal Replication & $9.89 \mathrm{E}-16$ & 17 \\
\hline Mitotic Roles of Polo-Like Kinase & $1.10 \mathrm{E}-10$ & 14 \\
\hline Role of BRCA1 in DNA Damage Response & $2.50 \mathrm{E}-09$ & 14 \\
\hline ATM Signaling & $2.96 \mathrm{E}-09$ & 15 \\
\hline
\end{tabular}

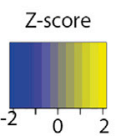

Cell cycle control of chromosomal replication
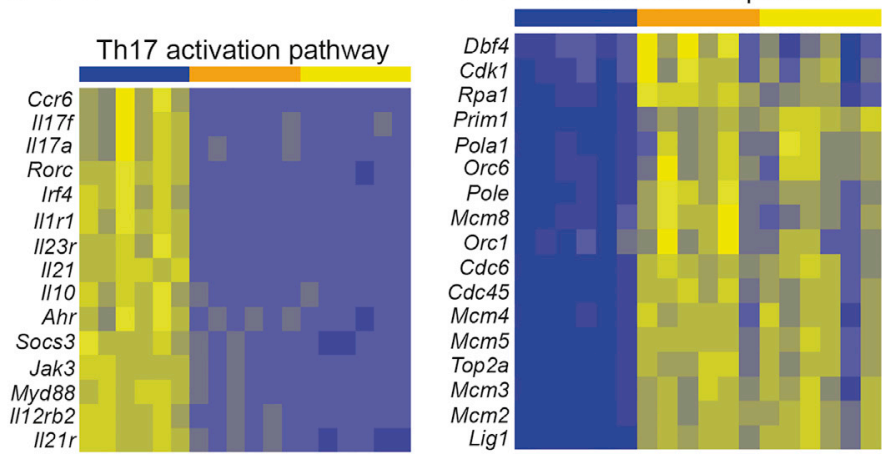
effects, we also measured COX1 and ND1 at $72 \mathrm{~h}$ and found them to be expressed at similar amounts to controls (data not shown).

Mitochondrial respiration supports the metabolic needs of proliferating cells through the regeneration of electron-accepting co-factors such as nicotinamide or flavin adenine dinucleotide (NAD ${ }^{+}$and FAD, respectively) (Sullivan et al., 2015). Consistent with this, both Arg $\mathrm{C}$ and Linezolid decreased the Th17 cell intracellular $\mathrm{NAD}^{+} / \mathrm{NADH}$ ratio after $48 \mathrm{~h}$ of treatment (Figures $4 \mathrm{~B}$ and $\mathrm{S} 4 \mathrm{~A})$. A reduced $\mathrm{NAD}^{+} / \mathrm{NADH}$ ratio leads to allosteric inhibition of the enzyme complex pyruvate dehydrogenase, which converts pyruvate into acetyl-CoA by decarboxylation. In these conditions, pyruvate would preferentially be converted into lactate (Holness and Sugden, 2003; Randle et al., 1963; Skrtić et al., 2011). This was corroborated by a drop in $\mathrm{pH}$ of the culture medium and a slight increase in lactate production by Arg C-treated cells (Figures S4B and S4C). Deficient electron flow from NADH to oxygen, together with a lack of mitochondrial-encoded subunits of complex V, $F_{1} F_{0}$-ATPase (namely ATP6 and ATP8), should hinder oxidative phosphorylation-derived ATP production. Accordingly, the ADP/ATP ratio was significantly increased in Arg C-treated cells compared to controls (Figure S4D). We also observed that Linezolid and Arg $\mathrm{C}$ modestly increased the degree of AMPK phosphorylation (pAMPK, Figure S4E). However, exogenous ATP supplementation was unable to rescue cytokine production in either of the treatment groups (Figure S4F).

As expected, Arg C and Linezolid-treated cells had a lower basal and carbonyl cyanide-p-trifluoromethoxyphenylhydrazone (FCCP)-stimulated maximal cellular respiration (Figures $4 \mathrm{C}$ and 4D). The profound effects on mitochondria elicited by Arg $C$ were also observed by electron microscopy: in contrast to the normal round-shaped mitochondria (Buck et al., 2016), Arg Ctreated Th17 cells had elongated mitochondria with loosened cristae (Figure 4E). After $96 \mathrm{~h}$ of culture, mitochondria were swollen or sac-shaped and had a morphology reminiscent of that of this organelle in cells devoid of mtDNA ( $\rho^{0}$ cells) (Armand et al., 2004). Similar to $\rho^{0}$ cells (Appleby et al., 1999), Arg Ctreated cells were able to maintain their mitochondrial membrane potential (Figure S4G). While the loss of mtDNA-encoded subunits was evident at $48 \mathrm{~h}, \mathrm{IL}-17$ production was comparable to controls at this time point (Figure 4F). These findings hinted that initial Th differentiation steps were unaffected. To confirm this, we measured the expression of the Th cell master transcription factors. Indeed, Arg C did not affect the expression of T-bet,
GATA-3, or ROR $\gamma$ t in Th1, Th2, and Th17 cells, respectively (Figures S5A-S5C); this strongly suggested that Arg C impaired cytokine production rather than Th commitment. Nevertheless, considering our transcriptomic data showed cell cycle pathways to be dysregulated (Figures $3 \mathrm{E}$ and $3 \mathrm{~F}$ ), we investigated the relationship between proliferation and loss of cytokine production caused by Arg C. Using cells labelled with CellTrace, we observed that Arg $\mathrm{C}$ mildly impaired proliferation exclusively toward the final stages of differentiation (Figure S5D). Importantly, this moderate decline in cellular proliferation was not the main cause of cytokine inhibition, as cells from each individual cycle showed significantly reduced IL-17 production after $72 \mathrm{~h}$ of culture (Figure S5E). The upregulation of proliferation-associated genes by $\operatorname{Arg} C$ and Linezolid led us to wonder if these drugs were preventing $T$ cells from transitioning to a cytokine-production phenotype by maintaining them in a proliferative state. However, cytokine production was not recovered upon treatment with any of the tested classes of proliferation inhibitors (Figure S5F). Therefore, Arg C's inhibitory effect on cytokine production is not merely a consequence of impaired cellular division of effector cells.

\section{Gfm1 Loss Results in Deficient Mitochondrial} Translation and Impaired Th17 Effector Cell Function Aside from targeting mitoribosomes, Linezolid is also a weak inhibitor of monoamine oxidase (Quinn and Stern, 2009). Also, Args have been described as inhibitors of the proteasome (Loizidou and Zeinalipour-Yazdi, 2014; Nickeleit et al., 2008). To exclude that any of these side effects were responsible for the immunosuppressive effects of these drugs, we genetically targeted mitochondrial protein synthesis in T cells. As the target of Linezolid is the mitoribosome, which consists of several proteins and rRNAs, we focused instead on Gfm1, the gene encoding mEF-G1, located on chromosome 3 (Gao et al., 2001). Given that ubiquitous deletion of $\mathrm{Gfm} 1$ is lethal at pre-weaning stages, we generated an inducible, $\mathrm{T}$ cell-specific, $\mathrm{Gfm} 1^{-1-}$ mouse strain (T-Gfm1 $1 \Delta$ ). Mice expressing a CD4-specific, tamoxifeninducible Cre enzyme (Cd4-cre $\left.{ }^{\mathrm{ERT} 2 / \mathrm{WT}}\right)$ were crossed with mice carrying a loxP-flanked exon 4 in the Gfm 1 gene (Gfm $1^{\text {flox/flox }}$ ) (Figure 5A). Except for a modest increase in the proportion of single-positive (SP) $C D 8^{+}$population within the thymus of T-Gfm1 $\Delta$ mice, immune homeostasis was not significantly affected by any of the used combinations of Gfm1 and Cd4 transgenic alleles (Figures S6A and S6B). In contrast to $\mathrm{Gfm} 1^{-1-}$ mice, T-Gfm1 1

Figure 3. Inhibiting Mitochondrial Translation with Arg C Inhibits Th17 Cell Function

(A) Chemical structure of Arg C.

(B) Left: mouse naive $\mathrm{CD} 4^{+} \mathrm{T}$ cells cultured for 4 days under Th17 cell polarizing conditions in the presence of Arg $\mathrm{C}$ or vehicle (DMSO). Cells were stained for intracellular IL-17 and gated on live CD4 ${ }^{+} \mathrm{T}$ cells. Bar graphs show \% of IL-17 ${ }^{+}$cells (top left) amongst total live $\mathrm{CD} 4^{+} \mathrm{T}$ cells (bottom left). Right: human $\mathrm{CD} 4^{+}$ $\mathrm{CD}_{5} \mathrm{RO}^{-}$naive T cells isolated from cord blood were cultured for 6 days under Th17 cell polarizing conditions and treated with Arg C or vehicle (DMSO). Cells were stained for intracellular IL-17, gated on live $\mathrm{CD} 4^{+} \mathrm{T}$ cells. Graphs contain the data of five individual donors, indicated by connected dots. The values represent $\%$ of IL- $-17^{+}$cells amongst live $\mathrm{CD} 4^{+}$cells (above) and the $\%$ of viable $\mathrm{CD} 4^{+}$cells (below).

(C) Mitochondrial translation products in EL-4 cells pre-incubated for $1 \mathrm{~h}$ with $\operatorname{Arg} \mathrm{C}$, $\operatorname{Arg} \mathrm{F}$, or vehicle (DMSO) and radioactively labeled with $\left[{ }^{35} \mathrm{~S}\right]-\mathrm{methionine}$. (D-F) Mouse naive CD4 ${ }^{+} T$ cells were cultured under Th17 cell polarizing conditions in the presence of Arg C (60 nM), Linezolid (100 $\left.\mu M\right)$, or DMSO. (D) Venn diagrams showing the number of genes differentially up (left) or downregulated (right) by Linezolid versus Arg C, DMSO versus Arg C, and DMSO versus Linezolid. The overlapping genes are those found in both conditions (E). Top canonical pathways up or downregulated by both Arg C and Linezolid. (F) Heat maps showing expression of genes among three selected relevant pathways.

Results (B, left) are the pooled means of technical replicates from three independent experiments, with error bars representing the SD of the pooled means. ${ }^{*} p<$ $0.05,{ }^{\star \star} p<0.01$, and ${ }^{* \star *} p<0.001$. Representative results of two $(C)$ experiments. Genes $(E)$ are included if they were found to be up or downregulated in both independent experiments performed. See also Figures S2 and S3. 
A

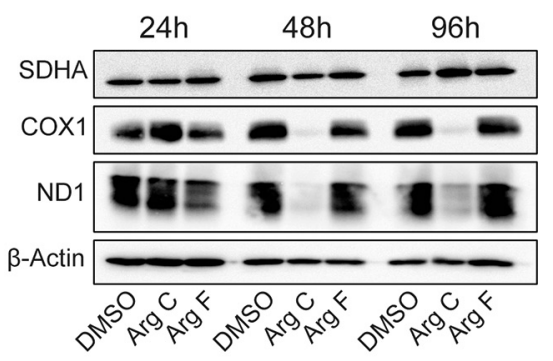

$\operatorname{Arg} C(n M)$

C

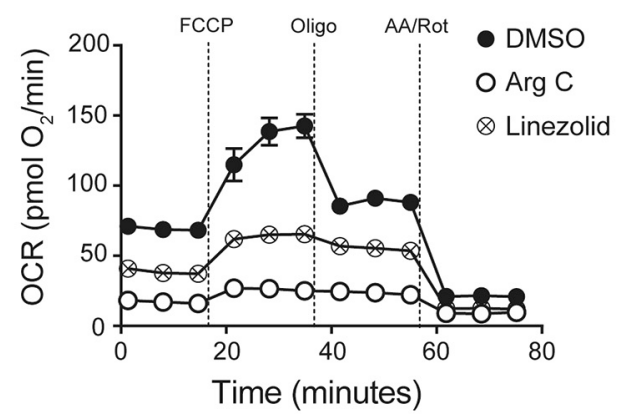

E

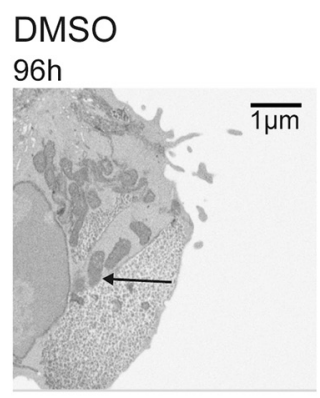

Naive T cells

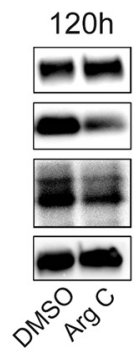

socos
B

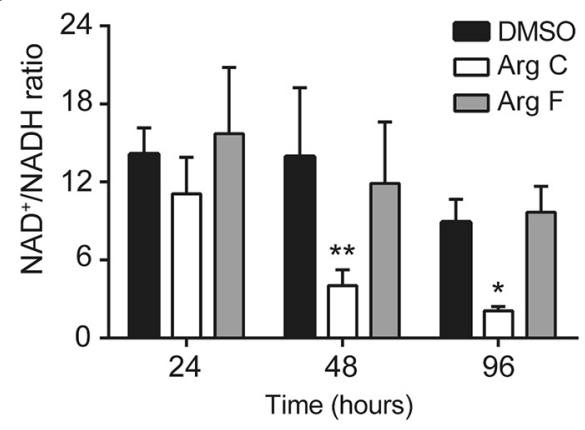

D
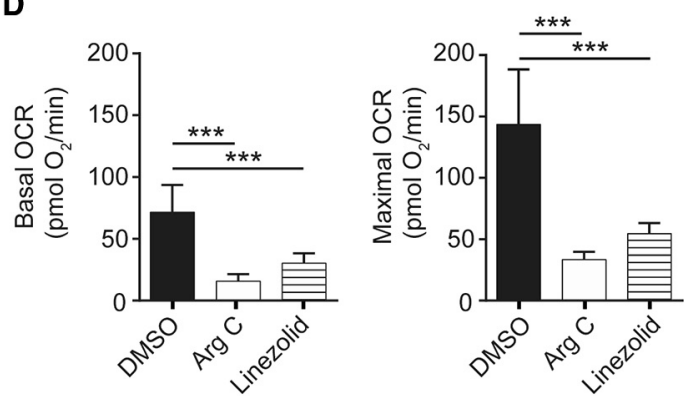

$\mathbf{F}$

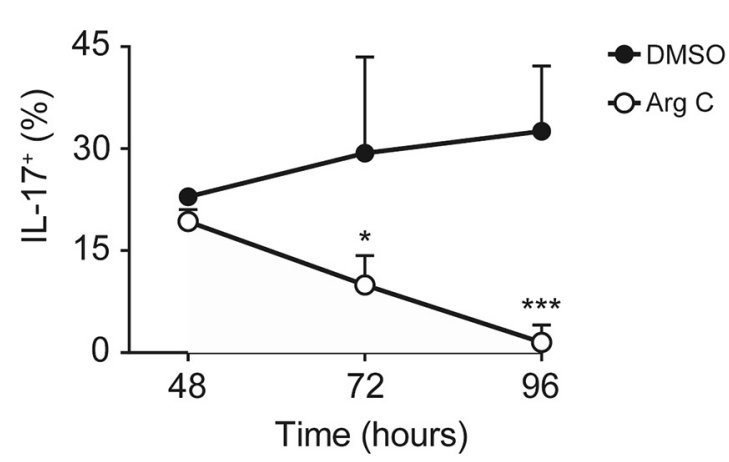

Figure 4. Arg C Treatment Selectively Affects High Proliferating Cells, Leading to Mitochondrial Dysfunction Naive CD4 ${ }^{+}$T cells were cultured under Th17 cell polarizing conditions in the presence of $\operatorname{Arg} C$ (60 nM), Arg F (60 nM), Linezolid (100 $\mu$ M), or vehicle (DMSO). (A) SDHA, ND1, and COX1 were quantified by western blot at the indicated time points.

(B) $\mathrm{NAD}^{+} / \mathrm{NADH}$ ratio measured at the indicated time points. 
mice are viable and expressed normal amounts of COX1 in their $\mathrm{CD}^{+} \mathrm{T}$ cells, indicative of functional mitochondrial translation (Figures 5B and S6C). Upon treatment with 4-hydroxytamoxifen (4-OHT), COX1 expression dropped in $\mathrm{CD}^{+}{ }^{+} \mathrm{T}$ cells from TGfm1 $1 \Delta$ mice in comparison to those still harboring Gfm1 WT alleles, either in a haplo-sufficient form (T-Gfm $1^{\text {het: }}$ Gfm $1^{\text {flox/WT }}$ Cd4cre ${ }^{\mathrm{ERT} 2 \mathrm{WT}}$ ) (Figure 5B) or lacking Cre-recombinase activity

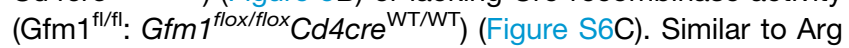
$\mathrm{C}$, differentiation of 4-OHT-treated naive $\mathrm{T}$ cells isolated from $\mathrm{T}$-Gfm1 $\Delta$ mice under Th17 cell-skewing conditions yielded a significantly reduced frequency of IL-17-expressing cells (Figures 5C and S6D). Finally, we demonstrated that tamoxifenmediated genetic deletion of $\mathrm{Gfm} 1$ in $\mathrm{CD}^{+}$cells from $\mathrm{T}$-Gfm1 $\Delta$ mice, led to significant protection from the development of EAE. Mice retaining a functional $\mathrm{Gfm} 1$ allele in $\mathrm{CD} 4^{+}$cells (T-Gfm $1^{\text {het }}$ ) were more susceptible to symptoms of the disease (Figure 5D) and had higher numbers and percentages of MOGspecific IL-17- and IFN- $\gamma$-producing Th cells in the CNS (Figure $5 \mathrm{E}$ ). Taken together, our results indicate that loss of mitochondrial translation in T cells, either genetically or pharmacologically, restrains Th17 cell function. We further show that mitochondrial translation is necessary for $T$ cell pathogenicity in vivo and could represent a therapeutic target to halt Th cell aberrant responses.

\section{Enabling Mitochondria-Independent NAD ${ }^{+}$}

Regeneration Facilitates Cytokine Production in Arg C and Linezolid-Treated Cells

Without electron acceptors, cells with dysfunctional mitochondria cannot regenerate cellular $\mathrm{NAD}^{+}$(Sullivan et al., 2015). As loss of mitochondrial translation reduces the $\mathrm{NAD}^{+} / \mathrm{NADH}$ ratio in differentiating $T$ cells, we hypothesized that facilitating NAD ${ }^{+}$ regeneration could partially restore cytokine production. To avoid any metabolic biases due to supplementation of the culture medium with exogenous metabolites, we supplemented it with lactate oxidase (Lox), allowing extracellular lactate to be converted to pyruvate. Pyruvate can then re-enter the cell and be converted back to lactate, regenerating a molecule of $\mathrm{NAD}^{+}$ in the process (Figure $6 \mathrm{~A}$ ). $\mathrm{H}_{2} \mathrm{O}_{2}$ generated by Lox was toxic at relatively low concentrations of the enzyme (data not shown). To prevent toxicity, we supplemented the medium with Catalase (Cat). The addition of both enzymes (LoxCat) rescued IL-17 production in both Arg C- and Linezolid-treated cells. This effect was not mediated by Cat, as Cat-exposed Arg C- and Linezolid-treated cells failed to produce significant amounts of cytokines (Figure 6B). LoxCat-exposed cells had a higher IL-17 production and $\mathrm{NAD}^{+} / \mathrm{NADH}$ ratio than that of the respective controls (Figures 6B and 6C). Supplementation of the culture medium with pyruvate equally restored cytokine production (Figure 6D). To uncouple this phenotype from other potential cellular roles of pyruvate, we supplemented the medium with $\alpha$-ketobutyrate $(\alpha-K B)$. $\alpha-K B$ can also be reduced by lactate dehydrogenase $(\mathrm{LDH})$ to regenerate $\mathrm{NAD}^{+}$(Sullivan et al., 2015) and was also able to rescue cytokine production in Arg C- and Linezolid-treated Th17 cells (Figure 6D). It has recently been shown that, when cellular respiration is impaired, serine catabolism via the mitochondrial folate pathway is responsible for the accumulation of NADH (Yang et al., 2020). Therefore, to understand if this pathway was responsible for $\mathrm{NAD}^{+}$depletion (and presumably, loss of cytokine production) upon Arg C and Linezolid treatment, we incubated these cells with DS18561882. DS18561882 is an inhibitor of methylenetetrahydrofolate dehydrogenase 2 (MTHFD2), a mitochondrial enzyme of the folate pathway that catalyzes an $\mathrm{NAD}^{+}$-consuming step. By treating cells at $24 \mathrm{~h}$ of culture, we hypothesized that we would be able to mitigate the observed drop in the intracellular $\mathrm{NAD}^{+} / \mathrm{NADH}$ ratio observed from $48 \mathrm{~h}$ onwards of Arg C or Linezolid treatment (Figure 4B), and, consequently rescue cytokine production. As surmised, DS18561882 was able to mitigate the inhibitory effect of Arg C and Linezolid upon IL-17 production (Figure 6E). Therefore, RAbos appear to downregulate Th17 cell function and cytokine production by compromising mitochondrial and, consequently, cellular $\mathrm{NAD}^{+}$-regeneration.

\section{DISCUSSION}

It is well established that some RAbos can inhibit mitoribosomes, and some have been described as immunosuppressive. For example, Chloramphenicol diminishes neutrophil extracellular trap release and Doxycycline inhibits $B$ cell class switching and IgM secretion (Bystrzycka et al., 2017; Kuzin et al., 2001). However, how the reduction of immune cell function occurred is not well understood. We have shown here that inhibition of mitochondrial protein synthesis by antibiotics can reduce Th cell cytokine secretion. Certain clinical observations suggest that Linezolid is immunosuppressive: as previously mentioned, Linezolid treatment confers an increased risk of fungal and Gramnegative infections (Falagas and Vardakas, 2008; Wilcox et al., 2009). Th17 cell function is necessary for mounting antifungal and antibacterial responses. As Linezolid is active exclusively against Gram-positive bacteria, we postulated that Linezolid facilitates opportunistic fungal or Gram-negative infections by dampening Th17 cell function. Importantly, we found Linezolid to inhibit both mitochondrial translation and Th17 cell function in vitro at concentrations routinely achieved during clinical administration (Bosso et al., 2004). We also showed that Linezolid prevented the development of self-reactive $T$ cells in the $\mathrm{T}$ cell-mediated autoimmunity EAE model. Thus, repurposing Linezolid as an immunosuppressive drug resulted in significant protection from pathogenic $\mathrm{T}$ cell infiltration and led to absent

$\overline{(C \text { and } D) ~(C) ~ R e p r e s e n t a t i v e ~ p l o t ~ o f ~ o x y g e n ~ c o n s u m p t i o n ~ r a t e ~(O C R) ~ a t ~} 72 \mathrm{~h}$ of culture and (D) respective basal (before drug addition) and maximal (after FCCP addition) respiratory activity of the cells. OCR is reported as picomoles (pmol) of $\mathrm{O}_{2}$ per minute. Oligo, oligomycin; FCCP, carbonyl cyanide-p-trifluoromethoxyphenylhydrazone; Rot, rotenone; AA, antimycin A.

(E) Representative electronic microscopy images show mitochondria morphology of Arg C- (60 nM) or DMSO-treated naive T cells from $48 \mathrm{~h}$ of culture. (F) Cells were stained for intracellular IL-17. The graph shows $\%$ of IL-17 ${ }^{+}$cells amongst total live CD4 $4^{+} \mathrm{T}$ cells after 48,72 , and $96 \mathrm{~h}$ of culture.

Statistical significance was determined using two-way ANOVA with Bonferroni multiple corrections test. Representative results of three (A), five (C), and one (E) experiments are shown. Results are pooled means of technical replicates from three (B and F) and five (D) independent experiments, with error bars representing the SD of pooled means. ${ }^{*} p<0.05,{ }^{* \star} p<0.01$, and ${ }^{* \star *} p<0.001$. See also Figures S4 and S5. 
A

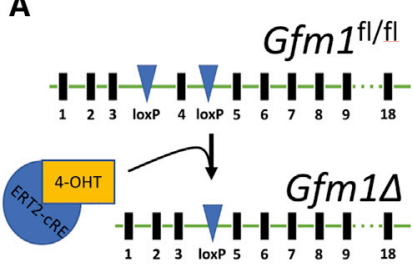

C

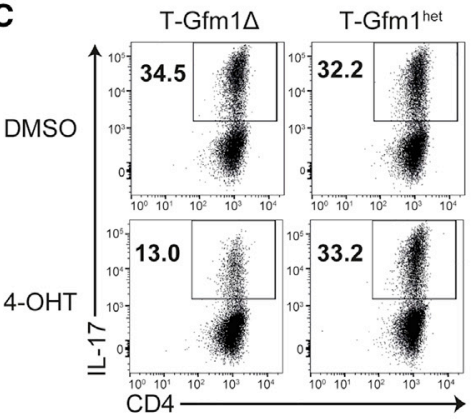

B

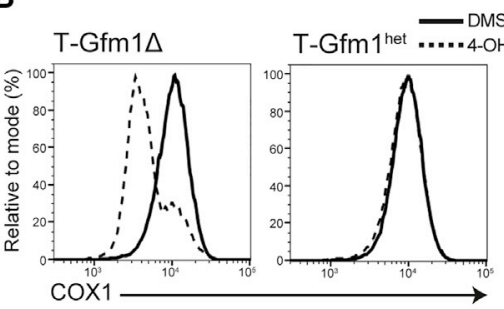

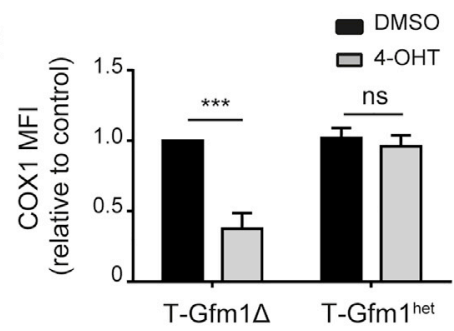

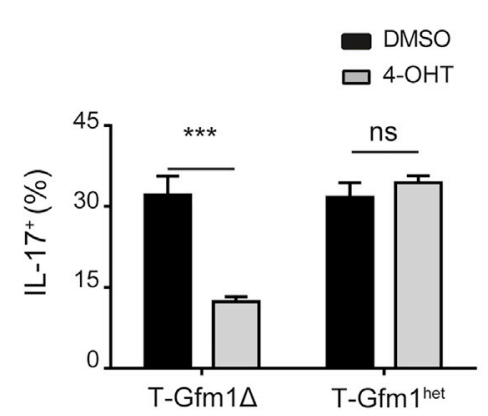

D

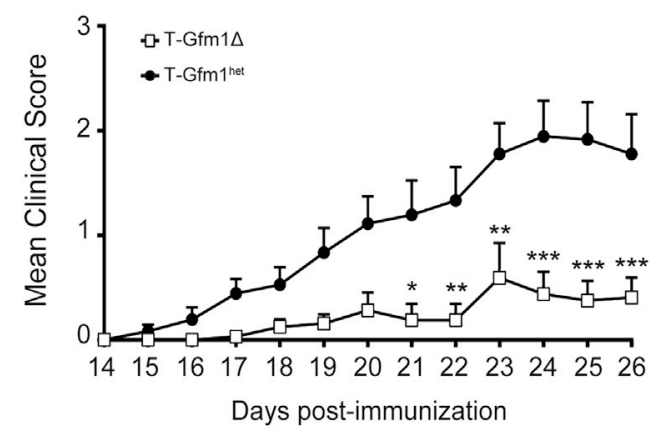

E
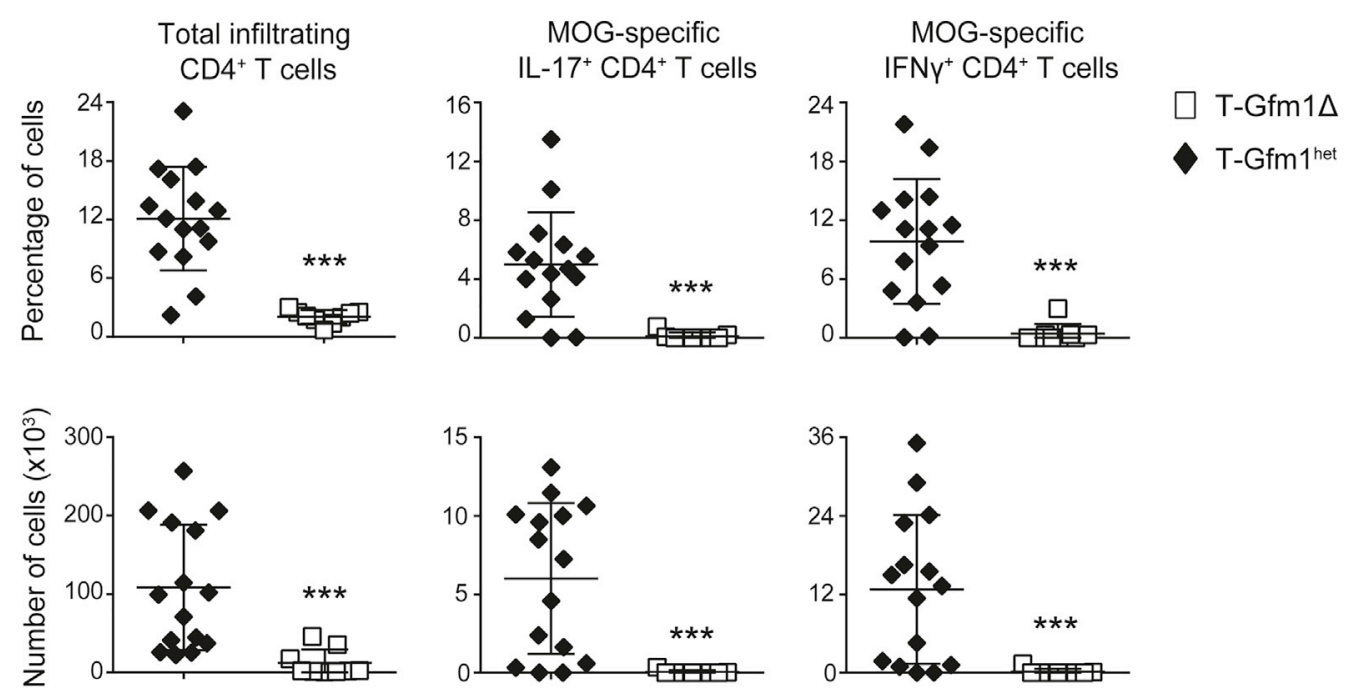

Figure 5. T Cell-Specific Gfm1 Deletion Attenuates Th17 Cell-Associated Cytokine Production and Mitigates the Development of EAE in MOG-Immunized Mice

(A) Generation of the CD4-specific, tamoxifen-inducible Cre mouse line. The loxP-flanked exon 4 of the Gfm1 gene is deleted after exposure to tamoxifen. 
(or mild) EAE symptoms. However, future studies will be necessary to determine if $\mathrm{T}$ cell-suppression by Linezolid contributes to the progression of infections.

To further study the role of mitochondrial translation in T cells, we searched for alternative methods to inhibit this process. In light of the indispensable role of $\mathrm{mEF}-\mathrm{G} 1$ in catalyzing the translocation of mitoribosomes during mitochondrial protein translation (Bhargava et al., 2004; Tsuboi et al., 2009), we made use of Arg C to hinder mEF-G1's activity during Th cell differentiation. Murine mEF-G1 shares $89 \%$ sequence identity with the human homologue mEF-G1 (Gao et al., 2001), and accordingly, Arg C was active against both human and mouse Th17 cells. The similarities in the gene transcriptional changes of Arg C- and Linezolidtreated cells further confirmed that targeting mitochondrial translation with either compound leads to analogous cellular effects. Using Arg C, we determined that differentiating $T$ cells are highly reliant on mitoribosomes to keep up with ETC biosynthetic demands. Notably, although Arg C inhibited mitochondrial protein synthesis after $1 \mathrm{~h}$ of treatment, the lack of mitochondrial-encoded and -translated ETC subunits was first observed $48 \mathrm{~h}$ after cell activation. At $24 \mathrm{~h}$, the majority of cells had not yet proliferated (Jelley-Gibbs et al., 2000) and, presumably, did not need to synthesize large amounts of ETC subunits. Between 24 and $48 \mathrm{~h}$, cell growth and division would require an increase in mitochondrial mass and proteome; therefore, an impairment of the mitochondrial translation machinery would render cells unable to keep up with the cellular demand for increased synthesis of ETC subunits. Ultimately, this would "dilute" pre-existing mitochondrial-encoded proteins such as COX1 and ND1 amongst daughter cells. Consequently, interfering with mitochondrial translation might deplete $\mathrm{mtDNA}$-encoded proteins more quickly in rapidly dividing cells such as activated T cells (Fu et al., 2017), while non-proliferative cells or tissues should be able to retain their ETC subunits for longer. Accordingly, we showed that naive T cells exposed to Arg $\mathrm{C}$ for as long as $120 \mathrm{~h}$ still expressed both COX1 and ND1.

Activated $\mathrm{CD}^{+} \mathrm{T}$ cells in the presence of Arg C, subjected to a gradual loss of ETC integrity, displayed reduced oxygen consumption and concomitant loss of electron acceptors such as $\mathrm{NAD}^{+}$. To circumvent this, cells are forced to convert pyruvate into lactate. As fermentation of glucose into lactate does not yield net $\mathrm{NAD}^{+}$(Almeida et al., 2016), over time the concentration of this cofactor required to support essential oxidative metabolic reactions in proliferating cells decreases. Accordingly, Th17 cells treated with $\mathrm{Arg} \mathrm{C}$ display reduced $\mathrm{NAD}^{+} / \mathrm{NADH}$ ratios and respiration and increased lactate secretion. Inhibition of mitochondrial translation by Arg $\mathrm{C}$ did not influence mitochondrial mem- brane potential. In this respect, studies on cells lacking mtDNA, termed $\rho^{\circ}$, revealed that these cells display a mitochondrial membrane potential high enough to sustain the import of nuclear-encoded proteins. The mechanism is thought to involve an electrogenic exchange of $\mathrm{ATP}^{4-}$ for $\mathrm{ADP}^{3-}$ by the adenine nucleotide carrier and maintained by an incomplete $F_{1} F_{0^{-}}$ ATPase (Appleby et al., 1999; Buchet and Godinot, 1998; Smith and Thorsness, 2005). The maintenance of mitochondrial membrane potential is also a strong indication that loss of mitochondrial translation does not fully compromise mitochondrial or cellular integrity, which may explain why cellular viability is unaffected by RAbos. Furthermore, ATP consumption to maintain the membrane potential is likely to consume glycolysis-derived ATP and is in agreement with the increased ADP/ATP ratio and degree of AMPK phosphorylation measured in Arg C-treated cells.

Several glycolysis-associated genes were downregulated by both Arg $\mathrm{C}$ and Linezolid when compared to controls in our RNA-seq data. The metabolic stress elicited by loss of mitochondrial translation may compromise the upregulation of glycolytic enzymes that supports anabolic metabolism in differentiating T cells (Wang et al., 2011). At the same time, inhibited respiration should place a higher demand for ATP synthesis on the glycolytic pathway, forcing the cells to convert a higher proportion of pyruvate to lactate to preserve the limited $\mathrm{NAD}^{+}$. This may explain why extracellular $\mathrm{pH}$ and lactate concentration are lower and higher, respectively, in cells with an apparently lower amount of glycolytic enzymes. Similarly, the RNA-seq data revealed an upregulation of genes associated with chromosomal replication, cell cycle, and/or DNA damage checkpoint regulation in Arg Cand Linezolid-treated Th17 cells. Given that Arg C is mildly anti-proliferative, it is plausible that loss of mitochondrial translation leads to replication stress and modulates proliferation at the transcriptional level during late stages of Th17 cell differentiation. Nevertheless, our results show that impaired proliferation cannot explain, per se, the lower degree of cytokine production. Indeed, upon activation, $\mathrm{CD}^{+} \mathrm{T}$ cells must undergo several rounds of proliferation to develop into cytokine-producing Th effector cells (Proserpio et al., 2016). While the loss of COX1 and ND1 occurs at $48 \mathrm{~h}$, neither proliferation nor IL-17 production is affected at this time point. Instead, we observed that if mitochondrial translation remained inhibited, cells progressively stopped producing IL-17. The downregulation of cytokines became evident from $72 \mathrm{~h}$ onwards and occurred in cells from all proliferation cycles, highlighting that Arg C's cytokine inhibition and anti-proliferative phenotypes are uncoupled. In this regard, Arg $C$ appeared to strictly affect effector function and not initial Th cell

(B and C) Sorted naive CD4 ${ }^{+}$T cells from T-Gfm1 $\Delta$ mice and littermate haplosufficient controls were pre-treated with 300 nM tamoxifen (4-OHT) or DMSO and maintained in a naive state 12 days prior to being differentiated under Th17 cell skewing conditions for 4 days. Intracellular COX1 and IL-17 were quantified by flow cytometry. (B) Representative histograms (left) of COX1 expression amongst CD4 ${ }^{+} \mathrm{T}$ cells. Bar graph (right) shows COX1 median fluorescence intensity (MFI) relative to DMSO. (C) Representative dot plots (left) show the percentage of IL-17 $7^{+}$amongst live $\mathrm{CD} 4^{+} \mathrm{T}$ cells. Bar graph (right) shows pooled means of the percentage of IL-17 $7^{+} \mathrm{CD} 4^{+} \mathrm{T}$ cells.

(D and E) T-Gfm1 $1 \Delta$ mice and haplosufficient controls were immunized with $\mathrm{MOG}_{35-55}$ in CFA and pertussis toxin to induce EAE. Tamoxifen was administered twice to every mouse, 3 and 5 days after induction of EAE. The graphs show the (D) mean clinical scores and (E) CNS-infiltrating cells for T-Gfm $1 \Delta$ mice and TGfm $1^{\text {het }}$ haplosufficient controls.

Bar graphs (B and C) contain the pooled means from the technical replicates of three individual experiments, with error bars representing the SD of the pooled means. Plots are obtained from the pooled data of two (D) and three (E) individual experiments, with error bars showing the (D) SEM of the pooled scores. Statistical significance was determined (D) using two-way ANOVA with Bonferroni multiple corrections test or with (E) an unpaired $t$ test per condition. * $p<0.05$, ${ }^{\star *} p<0.01$, and ${ }^{\star * *} p<0.001$.

See also Figure S6. 
A

\section{Extracellular space}

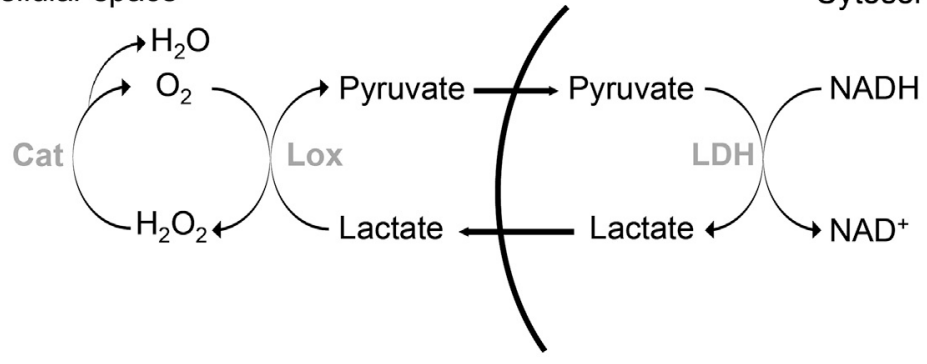

B

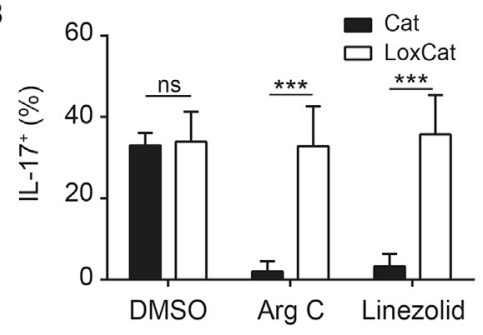

D

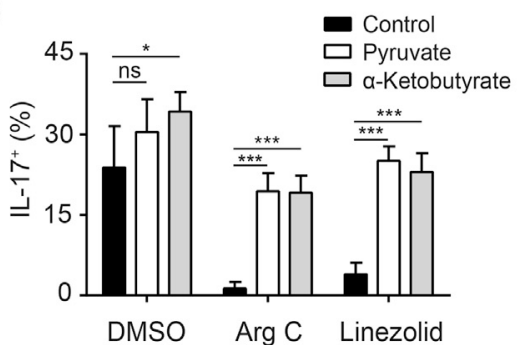

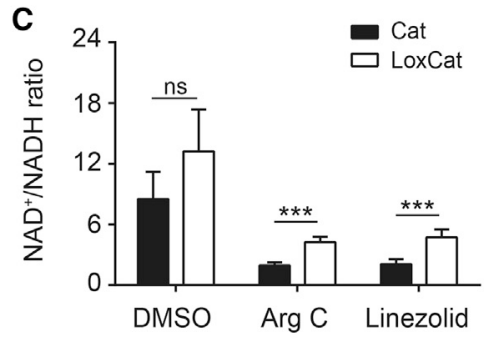

E

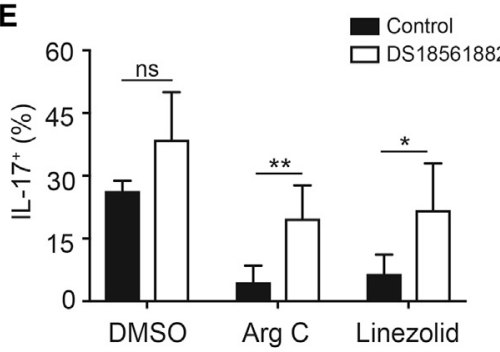

Figure 6. The Availability of Electron Acceptors Restores Cytokine Production in Th17 Cells with Impaired Mitochondrial Respiration

(A) Image depicting the pyruvate-lactate cycling and consequent intracellular regeneration of $\mathrm{NAD}^{+}$ enabled by exogenous addition of Lox $(25 \mathrm{mU})$ and Cat $(50 \mathrm{U})$.

(B-E) Naive CD4+ T cells were cultured under Th17 cell polarizing conditions in the presence of the indicated drugs. The culture medium was supplemented with ( $\mathrm{B}$ and $\mathrm{C}$ ) Cat alone (Cat) or in combination with Lox (LoxCat), (D) pyruvate or a-ketobutyrate (both $10 \mathrm{mM}$ ), or (E) DS18561882, and (B, $\mathrm{D}$, and $\mathrm{E}$ ) cytokine production and (c) $\mathrm{NAD}^{+} / \mathrm{NADH}$ ratios were measured.

Statistical significance was determined using multiple $t$ tests $(A, B, D$, and $E)$ or a two-way ANOVA with Bonferroni multiple corrections test (C). Bar graphs contain the pooled means from the technical replicates of three (D), four (B and C), and six (E) individual experiments, with error bars representing the SD of pooled means. Significance was determined as follows: ${ }^{*} p<0.05,{ }^{* *} p<0.01$, and ${ }^{\star \star *} p<0.001$

pairs Th17 and Th2 but exacerbates Th1 cell function (Baixauli et al., 2015). Mice lacking TFAM in all T cells $\left(\mathrm{Cd} 4^{\text {cre }}\right.$ Tfamflox/flox [CD4-TFAM $\Delta$ mice]) have more IFN- $\gamma$-producing cells in the intestinal lamina propria in a model of DSS-induced intestinal colitis (Baixauli et al., 2015). In a more recent publication, $\mathrm{T}$ cells from

transcriptional programs. This is consistent with Arg C-treated Th1, Th2, and Th17 cells retaining their expression of master transcription factors T-bet, GATA-3, and ROR $\gamma$ t, respectively.

It is now well accepted that mitochondrial metabolism goes hand-in-hand with $\mathrm{T}$ cell differentiation and function. Upon T cell activation, a metabolic reprogramming occurs, increasing the rates of glycolysis and respiration (Wang et al., 2011). Oligomycin (a complex $\mathrm{V}$ inhibitor) blocks $\mathrm{CD} 4^{+} \mathrm{T}$ cell proliferation and activation (Chang et al., 2013), deletion of Uqcrfs1 (a gene encoding for a subunit of CIII) impairs IL-2 production upon activation, and Cox10 (a gene encoding for a subunit of CIV) deficiency compromises $\mathrm{T}$ cell activation and proliferation, leading to apoptosis (Tarasenko et al., 2017). Mitochondria also produce reactive oxygen species that aid $\mathrm{T}$ cell activation (Sena et al., 2013), and cytokine production in differentiated Th1 and Th17 cells is reduced upon inhibition of specific ETC complexes (Bailis et al., 2019). Further, mtDNA content increases upon activation, suggesting that $T$ cell receptor stimulation is coupled to increased mitochondrial translation (D'Souza et al., 2007; RonHarel et al., 2016). While mEF-G1 is fundamental for mitochondrial translation, the transcription and translation of mtDNA-encoded genes depend on several other transcription factors and enzymes (El-Hattab et al., 2017), such as the mitochondrial transcription factor A (TFAM) (Araujo et al., 2018). A former study from the Mittelbrunn group suggests that $T$ cell-specific deletion of Tfam (and consequently, loss of mitochondrial translation) im-
CD4-TFAM $\Delta$ mice were shown to express more IFN- $\gamma$ and tumor necrosis factor $\alpha(\mathrm{TNF} \alpha)$ than wild-type controls (Desdín-Micó et al., 2020). These mice suffer from multi-organ morbidity and age and die earlier than wild-type controls; this effect was suggested to be mediated by intracellular $\mathrm{NAD}^{+} / \mathrm{NADH}$ imbalances. Possibly, NAD ${ }^{+}$-sensitive enzymes such as sirtuins or transcriptional regulators like $\mathrm{C}$-terminal-binding protein 1 and 2 can regulate gene expression in response to a drop in NAD ${ }^{+}$. However, if and how this occurs in T cells remains unexamined.

While the studies mentioned above suggest that TFAM deficiency in T cells has systemic autoimmune-like consequences, CD4-mediated gene deletion models are not specific for Th cells and also delete the floxed allele(s) in regulatory $\mathrm{T}$ (Treg) cells (Chen et al., 2003; Fontenot et al., 2003). In this regard, the Zhou group has shown that genetic deletion of Tfam in Treg cells leads to poor suppressive function and a higher degree of inflammation in a model of T cell transfer colitis (Fu et al., 2019). Treg cells lacking TFAM (from Foxp3 ${ }^{\text {Yfp-cre }}$ Tfam $^{\text {flox/flox }}$ [Foxp3-TFAM $\Delta$ ] mice) lose the expression of Foxp3 and produce cytokines such as IL-17 and IL-13. Th cells from Foxp3-TFAM $\Delta$ mice also express more IFN- $\gamma$, TNF $\alpha$, IL-4, IL-5, IL-13, and IL-17 in different organs and tissues (Fu et al., 2019). Importantly, while Foxp3TFAM $\Delta$ mice experience weight loss and exhibit a systemic autoimmunity phenotype starting from 4 to 6 weeks of age, CD4$\mathrm{TFAM} \Delta$ mice exhibit a milder or no phenotype until 10 weeks of age (Desdín-Micó et al., 2020; Fu et al., 2019). Therefore, deletion 
of TFAM in Th cells appears to delay the expected severe phenotype observed when this transcription factor is genetically ablated exclusively in Treg cells. Taken together, the results presented in this paper, as well as those from the Mittelbrunn and Zhou groups (Desdín-Micó et al., 2020; Fu et al., 2019), suggest that shorter-term inhibition of mitochondrial translation primarily impairs Th cell function and ameliorates autoimmunity. However, a longer-term inhibition ultimately appears to compromise Treg cell functionality. Animal models lacking TFAM specifically in Th cell subsets, while retaining TFAM-competent Treg cells (and vice versa), will be necessary to understand how inhibition of ETC biosynthesis individually affects Th and Treg cells. Furthermore, they would help to understand the pharmacological window and dose where mitochondrial translation inhibition-mediated immunosuppression overcomes systemic inflammation due to impaired Treg cell function.

While our results may suggest repurposing RAbos as immunomodulatory drugs, this might be a double-edged sword given a potential negative impact on gut flora (Hagan et al., 2019; Pamer, 2016). Also, widespread usage of Linezolid in an autoimmune setting might speed up the dissemination of bacterial strains resistant to this reserve antibiotic. Antibiotics that are not routinely used in human medicine, such as Thiamphenicol, could be further explored as immunomodulators. Importantly, Args display poor antibacterial and antifungal properties and are not currently used as antibiotics in the clinic (Sasse et al., 2002). Furthermore, inhibition of $\mathrm{mEF}-\mathrm{G} 1$ by $\mathrm{Arg} \mathrm{C}$ blocked mitochondrial translation in Th17 cells at concentrations $4-5$ orders of magnitude lower than Linezolid. Even though we lacked the means to develop a good in vivo administration method for Arg $\mathrm{C}$, we propose that further steps should be taken to adapt current or more potent mitochondrial translation inhibitors for therapeutic use. To encourage such efforts, we investigated the role of mEF-G1 in Th17 cell function in a $\mathrm{T}$ cell-specific $\mathrm{Gfm} 1^{-1-}$ mouse strain. Tamoxifen-mediated deletion validated that $\mathrm{mEF}-\mathrm{G} 1$ is necessary for T cells to maintain their effector function. Moreover, deleting Gfm 1 in $\mathrm{CD} 4^{+}$cells at the onset period of EAE induction protected against disease symptoms and provided strong evidence that this pathway is necessary for T cell-mediated pathogenicity. In conclusion, our results provide evidence to consider inhibition of mitochondrial translation as a method to halt pathological Th cell responses. Additionally, we identify mEF-G1 as a promising target to control this cellular process and achieve immunomodulation and highlight the ability of RAbos to alter host cell functions.

\section{STAR $\star$ METHODS}

Detailed methods are provided in the online version of this paper and include the following:

- KEY RESOURCES TABLE

- RESOURCE AVAILABILITY

○ Lead Contact

O Materials Availability

O Data and Code Availability

- EXPERIMENTAL MODEL AND SUBJECT DETAILS
O Mice
$\bigcirc$ Mouse T cell cultures
- Human T cell cultures

Naive T cell maintenance and Gfm1 deletion

○ Experimental autoimmune encephalomyelitis

- METHOD DETAILS

O Flow cytometry

○ Western blot

○ Metabolism analysis

Mitochondrial membrane potential measurement

Lactate measurement

$\mathrm{NAD}^{+} / \mathrm{NADH}$ ratio measurement

ADP/ATP ratio measurement

Mitochondrial translation assay

Electron microscopy analysis

- QUANTIFICATION AND STATISTICAL ANALYSIS

O RNA-seq dataset, quality control, and analysis

Statistical analysis

\section{SUPPLEMENTAL INFORMATION}

Supplemental Information can be found online at https://doi.org/10.1016/j. immuni.2020.11.001.

\section{ACKNOWLEDGMENTS}

We thank all members of the Institute of Infection Immunology at TWINCORE for discussion and support. We would like to acknowledge the assistance of the Cell Sorting Core Facility of the Hannover Medical School supported in part by the Braukmann-Wittenberg-Herz-Stiftung and the Deutsche Forschungsgemeinschaft. We thank Heinrich Steinmetz from Helmholtz Center for Infection Research for providing Arg C, Peter Rehling from University Medical Center (Göttingen) for providing resources to conduct mitochondrial translation assays, and the Department of Prenatal Medicine and Midwifery of the Medical School Hannover (MHH) for providing human cord blood. We would also like to thank the Teichmann Lab at the Wellcome Trust Sanger Institute, Dora Pedroso at Instituto Gulbenkian de Ciência, and Karsten Hiller's group at Technische Universität Braunschweig for technical support. This work was supported by grants from the Deutsche Forschungsgemeinschaft (CRC156) to T.S.; A.D.-L. was supported by the Hannover School for Biomedical Drug Research (HSBDR) and L.A. has received funding from the European Union's Horizon 2020 research and innovation program under the Marie Skłodowska-Curie grant agreement no. 675395. B.R.B was supported by the National Institutes of Health R01 HL56067 and R37 Al34495. L.F.M. was supported by the European Commission Horizon 2020 (ERC-2014-CoG 647888IPROTECTION).

\section{AUTHOR CONTRIBUTIONS}

Conceptualization, T.S.; Investigation, L.A., A.D.-L., C.N.C., G.M.C., M.G. C.H., N.A., S.D., and S.L.; Resources, B.N.L., L.S., M.K., and R.M.; Writing and Visualization, L.A., A.D.-L. C.N.C., and T.S., Critical Revision, L.F.M., L.B., B.N.L., and B.R.B.; Supervision, Project Administration, and Funding Acquisition, T.S.

\section{DECLARATION OF INTERESTS}

The authors declare no competing interests.

Received: November 10, 2019

Revised: September 16, 2020

Accepted: November 3, 2020

Published: November 24, 2020

\section{REFERENCES}

Almeida, L., Lochner, M., Berod, L., and Sparwasser, T. (2016). Metabolic pathways in T cell activation and lineage differentiation. Semin. Immunol. 28, 514-524. 
Appleby, R.D., Porteous, W.K., Hughes, G., James, A.M., Shannon, D., Wei, Y.H., and Murphy, M.P. (1999). Quantitation and origin of the mitochondrial membrane potential in human cells lacking mitochondrial DNA. Eur. J. Biochem. 262, 108-116.

Araujo, L.F., Siena, A.D.D., Plaça, J.R., Brotto, D.B., Barros, I.I., Muys, B.R., Biagi, C.A.O., Jr., Peronni, K.C., Sousa, J.F., Molfetta, G.A., et al. (2018). Mitochondrial transcription factor A (TFAM) shapes metabolic and invasion gene signatures in melanoma. Sci. Rep. 8, 14190.

Armand, R., Channon, J.Y., Kintner, J., White, K.A., Miselis, K.A., Perez, R.P., and Lewis, L.D. (2004). The effects of ethidium bromide induced loss of mitochondrial DNA on mitochondrial phenotype and ultrastructure in a human leukemia T-cell line (MOLT-4 cells). Toxicol. Appl. Pharmacol. 196, 68-79.

Bailis, W., Shyer, J.A., Zhao, J., Canaveras, J.C.G., Al Khazal, F.J., Qu, R., Steach, H.R., Bielecki, P., Khan, O., Jackson, R., et al. (2019). Distinct modes of mitochondrial metabolism uncouple $\mathrm{T}$ cell differentiation and function. Nature 571, 403-407.

Baixauli, F., Acín-Pérez, R., Villarroya-Beltrí, C., Mazzeo, C., Nuñez-Andrade, N., Gabandé-Rodriguez, E., Ledesma, M.D., Blázquez, A., Martin, M.A., Falcón-Pérez, J.M., et al. (2015). Mitochondrial Respiration Controls Lysosomal Function during Inflammatory T Cell Responses. Cell Metab. 22, 485-498.

Berod, L., Heinemann, C., Heink, S., Escher, A., Stadelmann, C., Drube, S., Wetzker, R., Norgauer, J., and Kamradt, T. (2011). PI3K $\gamma$ deficiency delays the onset of experimental autoimmune encephalomyelitis and ameliorates its clinical outcome. Eur. J. Immunol. 41, 833-844.

Bhargava, K., Templeton, P., and Spremulli, L.L. (2004). Expression and characterization of isoform 1 of human mitochondrial elongation factor $\mathrm{G}$. Protein Expr. Purif. 37, 368-376.

Bosso, J.A., Flume, P.A., and Gray, S.L. (2004). Linezolid pharmacokinetics in adult patients with cystic fibrosis. Antimicrob. Agents Chemother. 48, 281-284.

Buchet, K., and Godinot, C. (1998). Functional F1-ATPase essential in maintaining growth and membrane potential of human mitochondrial DNAdepleted rho degrees cells. J. Biol. Chem. 273, 22983-22989.

Buck, M.D., O'Sullivan, D., Klein Geltink, R.I., Curtis, J.D., Chang, C.H., Sanin, D.E., Qiu, J., Kretz, O., Braas, D., van der Windt, G.J., et al. (2016). Mitochondrial Dynamics Controls $T$ Cell Fate through Metabolic Programming. Cell 166, 63-76.

Bystrzycka, W., Manda-Handzlik, A., Sieczkowska, S., Moskalik, A., Demkow, U., and Ciepiela, O. (2017). Azithromycin and Chloramphenicol Diminish Neutrophil Extracellular Traps (NETs) Release. Int. J. Mol. Sci. 18, 2666.

Chang, C.-H., Curtis, J.D., Maggi, L.B., Jr., Faubert, B., Villarino, A.V., O'Sullivan, D., Huang, S.C.-C., van der Windt, G.J.W., Blagih, J., Qiu, J., et al. (2013). Posttranscriptional control of T cell effector function by aerobic glycolysis. Cell 153, 1239-1251.

Chen, W., Jin, W., Hardegen, N., Lei, K.J., Li, L., Marinos, N., McGrady, G., and Wahl, S.M. (2003). Conversion of peripheral CD4+CD25- naive T cells to CD4+CD25+ regulatory T cells by TGF-beta induction of transcription factor Foxp3. J. Exp. Med. 198, 1875-1886.

Chen, H., Zheng, J., Xue, L., Meng, Y., Wang, Y., Zheng, B., Fang, F., Shi, S., Qiu, Q., Jiang, P., et al. (2012). The 12S rRNA A1555G mutation in the mitochondrial haplogroup D5a is responsible for maternally inherited hypertension and hearing loss in two Chinese pedigrees. Eur. J. Hum. Genet. 20, 607-612. Chen, X., Bui, K.C., Barat, S., Thi Nguyen, M.L., Bozko, P., Sipos, B., Kalesse, M., Malek, N.P., and Plentz, R.R. (2017). Therapeutic effects of Argyrin F in pancreatic adenocarcinoma. Cancer Lett. 399, 20-28.

D'Souza, A.D., Parikh, N., Kaech, S.M., and Shadel, G.S. (2007). Convergence of multiple signaling pathways is required to coordinately up-regulate mtDNA and mitochondrial biogenesis during T cell activation. Mitochondrion 7, 374-385.

Degli Esposti, M., Chouaia, B., Comandatore, F., Crotti, E., Sassera, D., Lievens, P.M., Daffonchio, D., and Bandi, C. (2014). Evolution of mitochondria reconstructed from the energy metabolism of living bacteria. PLoS ONE 9, e96566.
Desdín-Micó, G., Soto-Heredero, G., Aranda, J.F., Oller, J., Carrasco, E., Gabandé-Rodríguez, E., Blanco, E.M., Alfranca, A., Cussó, L., Desco, M., et al. (2020). T cells with dysfunctional mitochondria induce multimorbidity and premature senescence. Science 368, 1371-1376.

El-Hattab, A.W., Craigen, W.J., and Scaglia, F. (2017). Mitochondrial DNA maintenance defects. Biochim Biophys Acta Mol Basis Dis 1863, 1539-1555. Falagas, M.E., and Vardakas, K.Z. (2008). Benefit-risk assessment of linezolid for serious gram-positive bacterial infections. Drug Saf. 31, 753-768.

Fontenot, J.D., Gavin, M.A., and Rudensky, A.Y. (2003). Foxp3 programs the development and function of CD4+CD25+ regulatory T cells. Nat. Immunol. 4, 330-336.

Fu, X., Liu, W., Huang, Q., Wang, Y., Li, H., and Xiong, Y. (2017). Targeting mitochondrial respiration selectively sensitizes pediatric acute lymphoblastic leukemia cell lines and patient samples to standard chemotherapy. Am. J. Cancer Res. 7, 2395-2405.

Fu, Z., Ye, J., Dean, J.W., Bostick, J.W., Weinberg, S.E., Xiong, L., Oliff, K.N., Chen, Z.E., Avram, D., Chandel, N.S., and Zhou, L. (2019). Requirement of Mitochondrial Transcription Factor A in Tissue-Resident Regulatory $\mathrm{T}$ Cell Maintenance and Function. Cell Rep. 28, 159-171.e4.

Gao, J., Yu, L., Zhang, P., Jiang, J., Chen, J., Peng, J., Wei, Y., and Zhao, S. (2001). Cloning and characterization of human and mouse mitochondrial elongation factor G, GFM and Gfm, and mapping of GFM to human chromosome 3q25.1-q26.2. Genomics 74, 109-114.

Gardete, S., and Tomasz, A. (2014). Mechanisms of vancomycin resistance in Staphylococcus aureus. J. Clin. Invest. 124, 2836-2840.

Hagan, T., Cortese, M., Rouphael, N., Boudreau, C., Linde, C., Maddur, M.S., Das, J., Wang, H., Guthmiller, J., Zheng, N.Y., et al. (2019). Antibiotics-Driven Gut Microbiome Perturbation Alters Immunity to Vaccines in Humans. Cell 178, 1313-1328.e13.

Häkli, S., Luotonen, M., Sorri, M., and Majamaa, K. (2015). Mutations in the two ribosomal RNA genes in mitochondrial DNA among Finnish children with hearing impairment. BMC Med. Genet. 16, 3.

Hashemian, S.M.R., Farhadi, T., and Ganjparvar, M. (2018). Linezolid: a review of its properties, function, and use in critical care. Drug Des. Devel. Ther. 12, 1759-1767.

Hellinger, W.C., and Brewer, N.S. (1999). Carbapenems and monobactams: imipenem, meropenem, and aztreonam. Mayo Clin. Proc. 74, 420-434.

Holness, M.J., and Sugden, M.C. (2003). Regulation of pyruvate dehydrogenase complex activity by reversible phosphorylation. Biochem. Soc. Trans. 31, 1143-1151.

Houtkooper, R.H., Mouchiroud, L., Ryu, D., Moullan, N., Katsyuba, E., Knott, G., Williams, R.W., and Auwerx, J. (2013). Mitonuclear protein imbalance as a conserved longevity mechanism. Nature 497, 451-457.

Jager, E., and Bass, R. (1975). Chloramphenicol/thiamphenicol and cycloheximide as tools for the measurement of mitochondrial protein synthesis in vitro during organogenesis of rat embryos. Naunyn Schmiedebergs Arch. Pharmacol. 290, 161-173.

Jelley-Gibbs, D.M., Lepak, N.M., Yen, M., and Swain, S.L. (2000). Two distinct stages in the transition from naive CD4 T cells to effectors, early antigendependent and late cytokine-driven expansion and differentiation. J. Immunol. 165, 5017-5026.

Josefsdottir, K.S., Baldridge, M.T., Kadmon, C.S., and King, K.Y. (2017) Antibiotics impair murine hematopoiesis by depleting the intestinal microbiota. Blood 129, 729-739.

Kohanski, M.A., Dwyer, D.J., and Collins, J.J. (2010). How antibiotics kill bacteria: from targets to networks. Nat. Rev. Microbiol. 8, 423-435.

Kuzin, I.I., Snyder, J.E., Ugine, G.D., Wu, D., Lee, S., Bushnell, T., Jr., Insel, R.A., Young, F.M., and Bottaro, A. (2001). Tetracyclines inhibit activated B cell function. Int. Immunol. 13, 921-931.

Lamb, R., Ozsvari, B., Lisanti, C.L., Tanowitz, H.B., Howell, A., MartinezOutschoorn, U.E., Sotgia, F., and Lisanti, M.P. (2015). Antibiotics that target mitochondria effectively eradicate cancer stem cells, across multiple tumor types: treating cancer like an infectious disease. Oncotarget 6, 4569-4584. 
Leach, K.L., Swaney, S.M., Colca, J.R., McDonald, W.G., Blinn, J.R., Thomasco, L.M., Gadwood, R.C., Shinabarger, D., Xiong, L., and Mankin, A.S. (2007). The site of action of oxazolidinone antibiotics in living bacteria and in human mitochondria. Mol. Cell 26, 393-402.

Liesa, M., and Shirihai, O.S. (2016). Mitochondrial Networking in T Cell Memory. Cell 166, 9-10.

Llobet, L., Bayona-Bafaluy, M.P., Pacheu-Grau, D., Torres-Pérez, E., Arbones-Mainar, J.M., Navarro, M.A., Gómez-Díaz, C., Montoya, J., LópezGallardo, E., and Ruiz-Pesini, E. (2017). Pharmacologic concentrations of linezolid modify oxidative phosphorylation function and adipocyte secretome. Redox Biol. 13, 244-254.

Loizidou, E.Z., and Zeinalipour-Yazdi, C.D. (2014). Computational inhibition studies of the human proteasome by argyrin-based analogues with subunit specificity. Chem. Biol. Drug Des. 84, 99-107.

Mao, Y., Dai, D., Jin, H., and Wang, Y. (2018). The risk factors of linezolidinduced lactic acidosis: A case report and review. Medicine (Baltimore) 97, e12114.

McKee, E.E., Ferguson, M., Bentley, A.T., and Marks, T.A. (2006). Inhibition of mammalian mitochondrial protein synthesis by oxazolidinones. Antimicrob. Agents Chemother. 50, 2042-2049.

Mestre, L., Carrillo-Salinas, F.J., Mecha, M., Feliú, A., Espejo, C., ÁlvarezCermeño, J.C., Villar, L.M., and Guaza, C. (2019). Manipulation of Gut Microbiota Influences Immune Responses, Axon Preservation, and Motor Disability in a Model of Progressive Multiple Sclerosis. Front. Immunol. $10,1374$.

Mortazavi, A., Williams, B.A., McCue, K., Schaeffer, L., and Wold, B. (2008). Mapping and quantifying mammalian transcriptomes by RNA-Seq. Nat. Methods 5, 621-628.

Moullan, N., Mouchiroud, L., Wang, X., Ryu, D., Williams, E.G., Mottis, A., Jovaisaite, V., Frochaux, M.V., Quiros, P.M., Deplancke, B., et al. (2015). Tetracyclines Disturb Mitochondrial Function across Eukaryotic Models: A Call for Caution in Biomedical Research. Cell Rep. 10, 1681-1691.

Mutnick, A.H., Biedenbach, D.J., Turnidge, J.D., and Jones, R.N. (2002). Spectrum and potency evaluation of a new oxazolidinone, linezolid: report from the SENTRY Antimicrobial Surveillance Program, 1998-2000. Diagn. Microbiol. Infect. Dis. 43, 65-73.

Nickeleit, I., Zender, S., Sasse, F., Geffers, R., Brandes, G., Sörensen, I., Steinmetz, H., Kubicka, S., Carlomagno, T., Menche, D., et al. (2008). Argyrin a reveals a critical role for the tumor suppressor protein p27(kip1) in mediating antitumor activities in response to proteasome inhibition. Cancer Cell 14, 23-35.

Nyfeler, B., Hoepfner, D., Palestrant, D., Kirby, C.A., Whitehead, L., Yu, R., Deng, G., Caughlan, R.E., Woods, A.L., Jones, A.K., et al. (2012). Identification of elongation factor $\mathrm{G}$ as the conserved cellular target of argyrin B. PLoS ONE 7, e42657.

Ochoa-Reparaz, J., Mielcarz, D.W., Ditrio, L.E., Burroughs, A.R., Foureau, D.M., Haque-Begum, S., and Kasper, L.H. (2009). Role of gut commensal microflora in the development of experimental autoimmune encephalomyelitis. J. Immunol. 183, 6041-6050.

Ónodi-Nagy, K., Kinyó, Á., Meszes, A., Garaczi, E., Kemény, L., and BataCsörgö, Z. (2015). Amoxicillin rash in patients with infectious mononucleosis: evidence of true drug sensitization. Allergy Asthma Clin. Immunol. 11, 1.

Pacheu-Grau, D., Gómez-Durán, A., Montoya, J., and Ruiz-Pesini, E. (2010). Influence of mtDNA genetic variation on antibiotic therapy. Pharmacogenomics 11, 1185-1187.

Pacheu-Grau, D., Gómez-Durán, A., Iglesias, E., López-Gallardo, E., Montoya, J., and Ruiz-Pesini, E. (2013). Mitochondrial antibiograms in personalized medicine. Hum. Mol. Genet. 22, 1132-1139.

Pamer, E.G. (2016). Resurrecting the intestinal microbiota to combat antibiotic-resistant pathogens. Science 352, 535-538.

Perry, C.M., and Jarvis, B. (2001). Linezolid: a review of its use in the management of serious gram-positive infections. Drugs 61, 525-551.
Priesnitz, C., and Becker, T. (2018). Pathways to balance mitochondrial translation and protein import. Genes Dev. 32, 1285-1296.

Prieto de Paula, J.M., Franco Hidalgo, S., and López Marcano, L.E. (2017). Anemia induced by linezolid. Med. Clin. (Barc.) 149, 369.

Proserpio, V., Piccolo, A., Haim-Vilmovsky, L., Kar, G., Lönnberg, T., Svensson, V., Pramanik, J., Natarajan, K.N., Zhai, W., Zhang, X., et al. (2016). Single-cell analysis of CD4+ T-cell differentiation reveals three major cell states and progressive acceleration of proliferation. Genome Biol. 17, 103. Quinn, D.K., and Stern, T.A. (2009). Linezolid and serotonin syndrome. Prim. Care Companion J. Clin. Psychiatry 11, 353-356.

Randle, P.J., Garland, P.B., Hales, C.N., and Newsholme, E.A. (1963). The glucose fatty-acid cycle. Its role in insulin sensitivity and the metabolic disturbances of diabetes mellitus. Lancet 1, 785-789.

Richter-Dennerlein, R., Oeljeklaus, S., Lorenzi, I., Ronsör, C., Bareth, B. Schendzielorz, A.B., Wang, C., Warscheid, B., Rehling, P., and Dennerlein, S. (2016). Mitochondrial Protein Synthesis Adapts to Influx of NuclearEncoded Protein. Cell 167, 471-483.e10.

Ron-Harel, N., Santos, D., Ghergurovich, J.M., Sage, P.T., Reddy, A., Lovitch, S.B., Dephoure, N., Satterstrom, F.K., Sheffer, M., Spinelli, J.B., et al. (2016). Mitochondrial Biogenesis and Proteome Remodeling Promote One-Carbon Metabolism for T Cell Activation. Cell Metab. 24, 104-117.

Sasse, F., Steinmetz, H., Schupp, T., Petersen, F., Memmert, K., Hofmann, H. Heusser, C., Brinkmann, V., von Matt, P., Höfle, G., and Reichenbach, H. (2002). Argyrins, immunosuppressive cyclic peptides from myxobacteria. I. Production, isolation, physico-chemical and biological properties. J. Antibiot. (Tokyo) 55, 543-551.

Sena, L.A., Li, S., Jairaman, A., Prakriya, M., Ezponda, T., Hildeman, D.A., Wang, C.R., Schumacker, P.T., Licht, J.D., Perlman, H., et al. (2013). Mitochondria are required for antigen-specific $\mathrm{T}$ cell activation through reactive oxygen species signaling. Immunity 38, 225-236.

Silhavy, T.J., Kahne, D., and Walker, S. (2010). The bacterial cell envelope. Cold Spring Harb. Perspect. Biol. 2, a000414.

Skarnes, W.C., Rosen, B., West, A.P., Koutsourakis, M., Bushell, W., lyer, V., Mujica, A.O., Thomas, M., Harrow, J., Cox, T., et al. (2011). A conditional knockout resource for the genome-wide study of mouse gene function. Nature 474, 337-342.

Skrtić, M., Sriskanthadevan, S., Jhas, B., Gebbia, M., Wang, X., Wang, Z., Hurren, R., Jitkova, Y., Gronda, M., Maclean, N., et al. (2011). Inhibition of mitochondrial translation as a therapeutic strategy for human acute myeloid leukemia. Cancer Cell 20, 674-688.

Sledzińska, A., Hemmers, S., Mair, F., Gorka, O., Ruland, J., Fairbairn, L., Nissler, A., Müller, W., Waisman, A., Becher, B., and Buch, T. (2013). TGF- $\beta$ signalling is required for $\mathrm{CD}^{+} \mathrm{T}$ cell homeostasis but dispensable for regulatory T cell function. PLoS Biol. 11, e1001674.

Smith, C.P., and Thorsness, P.E. (2005). Formation of an energized inner membrane in mitochondria with a gamma-deficient F1-ATPase. Eukaryot. Cell 4 2078-2086.

Sullivan, L.B., Gui, D.Y., Hosios, A.M., Bush, L.N., Freinkman, E., and Vander Heiden, M.G. (2015). Supporting Aspartate Biosynthesis Is an Essential Function of Respiration in Proliferating Cells. Cell 162, 552-563.

Tarasenko, T.N., Pacheco, S.E., Koenig, M.K., Gomez-Rodriguez, J., Kapnick, S.M., Diaz, F., Zerfas, P.M., Barca, E., Sudderth, J., DeBerardinis, R.J., et al. (2017). Cytochrome c Oxidase Activity Is a Metabolic Checkpoint that Regulates Cell Fate Decisions During T Cell Activation and Differentiation. Cell Metab. 25, 1254-1268.e7.

Tedesco, F.J. (1975). Ampicillin-associated diarrhea-A prospective study. Am. J. Dig. Dis. 20, 295-297.

Tsuboi, M., Morita, H., Nozaki, Y., Akama, K., Ueda, T., Ito, K., Nierhaus, K.H., and Takeuchi, N. (2009). EF-G2mt is an exclusive recycling factor in mammalian mitochondrial protein synthesis. Mol. Cell 35, 502-510.

Wang, R., Dillon, C.P., Shi, L.Z., Milasta, S., Carter, R., Finkelstein, D., McCormick, L.L., Fitzgerald, P., Chi, H., Munger, J., and Green, D.R. (2011). 
Immunity

Article

The transcription factor Myc controls metabolic reprogramming upon $T$ lymphocyte activation. Immunity 35, 871-882.

Wilcox, M.H., Tack, K.J., Bouza, E., Herr, D.L., Ruf, B.R., Ijzerman, M.M., Croos-Dabrera, R.V., Kunkel, M.J., and Knirsch, C. (2009). Complicated skin and skin-structure infections and catheter-related bloodstream infections: noninferiority of linezolid in a phase 3 study. Clin. Infect. Dis. 48 , 203-212.

Wilson, D.N., and Doudna Cate, J.H. (2012). The structure and function of the eukaryotic ribosome. Cold Spring Harb. Perspect. Biol. 4, a011536.

Xu, J., Schwartz, K., Bartoces, M., Monsur, J., Severson, R.K., and Sobel, J.D. (2008). Effect of antibiotics on vulvovaginal candidiasis: a MetroNet study. J. Am. Board Fam. Med. 21, 261-268.
Yang, L., Garcia Canaveras, J.C., Chen, Z., Wang, L., Liang, L., Jang, C., Mayr, J.A., Zhang, Z., Ghergurovich, J.M., Zhan, L., et al. (2020). Serine Catabolism Feeds NADH when Respiration Is Impaired. Cell Metab. 31, 809-821.e6.

Yunis, A.A., Manyan, D.R., and Arimura, G.K. (1973). Comparative effect of chloramphenicol and thiamphenicol on DNA and mitochondrial protein synthesis in mammalian cells. J. Lab. Clin. Med. 81, 713-718.

Zhang, L., Ging, N.C., Komoda, T., Hanada, T., Suzuki, T., and Watanabe, K. (2005). Antibiotic susceptibility of mammalian mitochondrial translation. FEBS Lett. 579, 6423-6427.

Zimmermann, P., Ziesenitz, V.C., Curtis, N., and Ritz, N. (2018). The Immunomodulatory Effects of Macrolides-A Systematic Review of the Underlying Mechanisms. Front. Immunol. 9, 302. 


\section{STAR $\star M E T H O D S$}

\section{KEY RESOURCES TABLE}

\begin{tabular}{|c|c|c|}
\hline REAGENT or RESOURCE & SOURCE & IDENTIFIER \\
\hline \multicolumn{3}{|l|}{ Antibodies } \\
\hline Hamster monoclonal anti-mouse CD3 & Bio X Cell & Cat\#: BE0001-1; RRID: AB_1107634 \\
\hline Hamster monoclonal anti-mouse CD28 & Bio X Cell & Cat\#: BE00015-1; RRID: AB_1107624 \\
\hline $\begin{array}{l}\text { Hamster monoclonal anti-mouse } \\
\text { IFN-gamma }\end{array}$ & Bio X Cell & Cat\#: BE0055; RRID: AB_1107694 \\
\hline Rat recombinant anti-mouse IL-12 p40 & Bio X Cell & Clone 17.8; RRID: AB_1107698 \\
\hline Rat monoclonal anti-mouse IL-4 & Bio X Cell & Cat\#: BE0045; RRID: AB_1107707 \\
\hline Rat monoclonal anti-mouse CD4 & eBioscience & Clone 48-0041; RRID: AB_1107642 \\
\hline Rat monoclonal anti-mouse/rat IL-17A & eBioscience & Clone eBio17B7; RRID: AB_763580 \\
\hline Rat monoclonal anti-mouse IL-13 & eBioscience & Clone eBio13A; RRID: AB_763559 \\
\hline Rat monoclonal anti-mouse IFN-gamma & eBioscience & Clone XMG1.2; RRID: AB_315403 \\
\hline $\begin{array}{l}\text { Mouse monoclonal anti-human/mouse } \\
\text { T-bet }\end{array}$ & eBioscience & Clone eBio4B10; RRID: AB_763634 \\
\hline Rat monoclonal anti-mouse RORgt & eBioscience & Clone B2D; RRID: AB_315403 \\
\hline $\begin{array}{l}\text { Rat monoclonal anti-mouse/human } \\
\text { GATA-3 }\end{array}$ & eBioscience & Clone TWAJ; RRID: AB_1963600 \\
\hline Rat monoclonal anti-mouse/rat FoxP3 & eBioscience & Clone FJK-16s; RRID: AB_1518812 \\
\hline $\begin{array}{l}\text { Mouse monoclonal anti-mouse CD154 } \\
\text { (CD40 Ligand) }\end{array}$ & eBioscience & Clone MR1; RRID: AB_2561561 \\
\hline Mouse monoclonal anti-mouse/rat COX1 & Abcam & Cat\#: ab154477 \\
\hline Mouse monoclonal anti-human CD4 & Invitrogen & Clone SK3; RRID: AB_1937227 \\
\hline Mouse monoclonal anti-human IL-17A & eBloscience & Clone eBio64DEC17; RRID: AB_11063994 \\
\hline $\begin{array}{l}\text { Mouse monoclonal anti-mouse anti- } \\
\text { human CD3 }\end{array}$ & BioLegend & 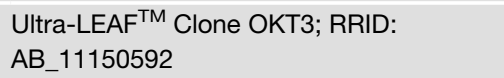 \\
\hline $\begin{array}{l}\text { Mouse monoclonal anti-mouse anti- } \\
\text { human } \mathrm{CD} 28\end{array}$ & BioLegend & $\begin{array}{l}\text { Ultra-LEAF }{ }^{\mathrm{TM}} \text { Clone CD28.2; RRID: } \\
\text { AB_314304 }\end{array}$ \\
\hline Recombinant anti-SDHA mAb & Abcam & aCat\#: ab139181 \\
\hline Recombinant anti-ND1 mAb & Abcam & Cat\#: ab181848 \\
\hline Recombinant anti-COX1 mAb & Abcam & Cat\#: ab139181 \\
\hline HIF-1 alpha Rabbit mAb & Novus biological & Cat\#: NB100-479: RRID: AB_10000633 \\
\hline AMPK $\alpha$ (23A3) Rabbit mAb & Cell Signaling & Cat\#: 2603; RRID:AB_490795 \\
\hline Phospho-AMPK $\alpha$ (Thr172) Rabbit mAb & Cell Signaling & Cat\#: 2535 \\
\hline Anti-rabbit lgG, HRP-linked Antibody & Cell Signaling & Cat\#: 7074; RRID:AB_2099233 \\
\hline Anti-mouse IgG, HRP-linked Antibody & Cell Signaling & Cat\#: 7076; RRID:AB_330924 \\
\hline $\begin{array}{l}\text { Rabbit polyclonal anti-human/mouse } \\
\text { beta-actin }\end{array}$ & Cell Signaling & Cat\#: 4967; RRID:AB_330288 \\
\hline \multicolumn{3}{|c|}{ Chemicals, Peptides, and Recombinant Proteins } \\
\hline IMDM GlutaMAX & Thermo Fisher & 3198-022 \\
\hline RPMI 1640 GlutaMAX & Thermo Fisher & $61870-010$ \\
\hline X-Vivo 15 medium & Lonza & BE02-060F \\
\hline Seahorse XF DMEM medium, pH 7.4 & Agilent & $103575-100$ \\
\hline Head-inactivated FCS & Biochrom & S 0115 - Lot\# 1289W \\
\hline Penicillin-streptomycin & Millipore & P0781 \\
\hline 2-mercaptoethanol & Gibco & \#21985-023 \\
\hline Recombinant human TGF-beta & Peprotech & $100-21$ \\
\hline
\end{tabular}




\begin{tabular}{|c|c|c|}
\hline \multicolumn{3}{|l|}{ Continued } \\
\hline REAGENT or RESOURCE & SOURCE & IDENTIFIER \\
\hline Recombinant murine IL-6 & Peprotech & 211-11B \\
\hline Recombinant murine IL-1beta & Peprotech & 211-11B \\
\hline Recombinant murine IL-12 & Peprotech & $210-12$ \\
\hline Recombinant murine IL-7 & Peprotech & $217-17$ \\
\hline Recombinant murine IL-4 & Preprotech & $214-14$ \\
\hline $\begin{array}{l}\text { Recombinant human IL-12 p70 (HEK293 } \\
\text { derived) }\end{array}$ & Peprotech & $200-12 \mathrm{H}$ \\
\hline Recombinant human IL-1beta & R\&D Systems & 201-LB-005 \\
\hline Recombinant human IL-23 & R\&D Systems & 1290-IL-010/CF \\
\hline Recombinant human IL-6 & Peprotech & $200-06$ \\
\hline Recombinant human IL-21 & Peprotech & $200-21$ \\
\hline Phorbol 12-myristate 13-acetate (PMA) & Sigma-Aldrich & P-8139 \\
\hline Ionomycin & Sigma-Aldrich & 10634 \\
\hline $\begin{array}{l}\text { Tetramethzlyrhodamine, Ethyl Ester, } \\
\text { Percholorate (TMRE) }\end{array}$ & Invitrogen & T669 \\
\hline Pierce RIPA Buffer & Thermo Scientific & 89900 \\
\hline Oligomycin & Sigma Aldrich & 75351 \\
\hline FCCP & Cayman & 15218 \\
\hline Rotenone & Cayman & 13955 \\
\hline Antimycin A & Sigma Aldrich & A8674 \\
\hline $\begin{array}{l}\text { XF Base Medium Minimal DMEM without } \\
\text { Phenol Red }\end{array}$ & Agilent & 103 \\
\hline Glucose $\geq 99.5 \% \mathrm{D}(+)$ & Roth & HN06.1 \\
\hline L-Glutamine & Biochrom AG & M11-004 \\
\hline Poly-D-lysine Hydrobromide & Sigma Aldrich & P6407 \\
\hline $\begin{array}{l}\text { RNAse OUT Ribonuclease inhibitor } \\
\text { (recombinant) }\end{array}$ & Invitrogen & $\# 10777-019$ \\
\hline CellTrace $^{\mathrm{TM}}$ Violet Cell Proliferation Kit & Life Technologies & \#65-0866-14 \\
\hline Fixable Viability Dye eFluor 780 & eBioscience & \#65-0865-14 \\
\hline BD GolgiStop & BD Biosciences & \#51-2092KZ \\
\hline $\begin{array}{l}\text { FoxP3/transcription factor staining } \\
\text { buffer set }\end{array}$ & eBiosciences & $\# 00-5523-00$ \\
\hline DMOG & Cayman chemicals & 71210 \\
\hline Lactate oxidase from Aerococcus viridans & Sigma & L9795-50UN \\
\hline Catalase, aspergillus niger & Merck Millipore & 219261-100KU \\
\hline Linezolid & Chem-Impex & 29723 \\
\hline Tigecycline hydrate & Sigma & PZ0021 \\
\hline Thiamphenicol & Chem-Impex & 29857 \\
\hline Vancomycin & Cayman-Chemical & $\# 15327$ \\
\hline FITC BrdU Flow Kit (RUO) & $\mathrm{BD}$ & 557891 \\
\hline DS18561882 inhibitor & Medchemexpress & HY-130251 \\
\hline Chaetocin from chaetomium minutum & Merck & C9492 \\
\hline DIF-1 & Sigma & SML0599 \\
\hline Mitomycin & Cayman & 11435 \\
\hline Paclitaxel & Cayman & 10461 \\
\hline SP600125 Inhibitor & Cayman & 10010466 \\
\hline ATP-polyamine-biotin & Medchemexpress & HY-D0183 \\
\hline $\begin{array}{l}\text { Adenosine } 5 \text { 'triphosphate disodium salt } \\
\text { hydrate }\end{array}$ & Merck & A26209 \\
\hline MCC905 & InvivoGen & inh-mcc \\
\hline
\end{tabular}




\begin{tabular}{|c|c|c|}
\hline \multicolumn{3}{|l|}{ Continued } \\
\hline REAGENT or RESOURCE & SOURCE & IDENTIFIER \\
\hline $\mathrm{MOG}_{35-55}$ peptide & Dr Werner Tegge, HZI Braunschweig & $\mathrm{N} / \mathrm{A}$ \\
\hline Corn oil & Sigma & C8267 \\
\hline (Z)-4-Hydroxytamoxifen & Caymen & 14854 \\
\hline Pertussis Toxin & Sigma-Aldrich & \#180 \\
\hline 1X Antibiotic Antimycotic Solution & Gibco & 15240062 \\
\hline \multicolumn{3}{|l|}{ Critical Commercial Assays } \\
\hline EasyStep $^{\mathrm{TM}}$ Mouse CD4+ Isolation Kit & StemCell technologies & 19852 \\
\hline $\begin{array}{l}\text { EasySep }^{\mathrm{TM}} \text { Human Naive CD4+ T Cell } \\
\text { Isolation Kit }\end{array}$ & StemCell technologies & 19555 \\
\hline Cell Trace Violet Cell Proliferation Kit & Invitrogen & C34557 \\
\hline $\begin{array}{l}\text { LIVE/DEAD Fixable Aqua Dead Cell Stain } \\
\text { Kit, for } 405 \mathrm{~nm} \text { excitation }\end{array}$ & Thermo Fisher & L34957 \\
\hline Seahorse XFe96 FluxPak & Agilent & $102416-100$ \\
\hline Qiagen RNAeasy Kit & Qiagen & $\# 74106$ \\
\hline Oligomycin & Sigma-Aldrich & 75351 \\
\hline FCCP & Cayman & 15218 \\
\hline Antimycin A & Abcam & ab141904 \\
\hline Rotenone & Cayman & 139995 \\
\hline Lactate Assay kit & Sigma-Aldrich & MAK064 \\
\hline NAD/NADH-Glo ${ }^{T M}$ Assay & Promega & G9072 \\
\hline ADP/ATP Ratio Assay kit & Abcam & ab83359 \\
\hline \multicolumn{3}{|l|}{ Deposited Data } \\
\hline Raw and processed RNA-seq data & Gene Expression Omnibus & GSE159401 \\
\hline \multicolumn{3}{|l|}{ Experimental Models: Cell Lines } \\
\hline EL4 & ATCC & ATCC ${ }^{\circledR}$ TIB-39 \\
\hline \multicolumn{3}{|l|}{ Experimental Models: Organisms/Strains } \\
\hline $\begin{array}{l}\text { Gfm1 1m1a(EUCOMM)Wtsi: C57BL/6NTac- } \\
\text { Gfm1 }\end{array}$ & EMMA & EM:05706 \\
\hline $\begin{array}{l}\text { Flp-expressing mice: B6;SJL-Tg(ACTFLPe) } \\
\text { 9205Dym/J }\end{array}$ & Jackson & Stock No: 003800 \\
\hline $\mathrm{Cd} 4 \mathrm{Cre} \mathrm{ERT}^{\mathrm{ER} / \mathrm{WT}}: \mathrm{Cd} 4^{\mathrm{tm} 1(\mathrm{cre} / \mathrm{ERT} 2) \mathrm{Thbu}}$ & (Sledzińska et al., 2013) & N/A \\
\hline \multicolumn{3}{|l|}{ Software and Algorithms } \\
\hline FlowJo software (Tree Star, Inc.) & FlowJo LLC & https://www.flowjo.com/ \\
\hline Ingenuity Pathway Analysis (IPA, QIAGEN) & Qiagen & N/A \\
\hline GraphPad Prism V6 or V7 & GraphPad Software & https://www.graphpad.com/ \\
\hline QIAGEN's CLC Genomics Workbench 8 & Qiagen & $\mathrm{N} / \mathrm{A}$ \\
\hline ImageJ & N/A & N/A \\
\hline Python matplotlib_venn library & Pypi & N/A \\
\hline ComplexHeatmap R package & Qiagen & N/A \\
\hline Atlas 5 & Zeiss & N/A \\
\hline
\end{tabular}

\section{RESOURCE AVAILABILITY}

\section{Lead Contact}

Further information and requests for resources and reagents should be directed to and will be fulfilled by the Lead Contact, Tim Sparwasser (sparwasser@uni-mainz.de)

\section{Materials Availability}

Mouse lines generated in this study will be maintained in the lead author's current institute's animal house and/or stored locally as frozen embryos and can be made available upon request. 
Requests for Argyrins should be directed to and fulfilled by the co-author Rolf Müller (rolf.mueller@helmholtz-hzi.de)

Data and Code Availability

The accession number for the sequencing data reported in this paper is GEO:GSE159401.

\section{EXPERIMENTAL MODEL AND SUBJECT DETAILS}

Mice

C57BL/6 mice were purchased from Jackson Laboratories. Gfm $1^{\text {flox/flox }}$ were generated by crossing mice carrying the heterozygous

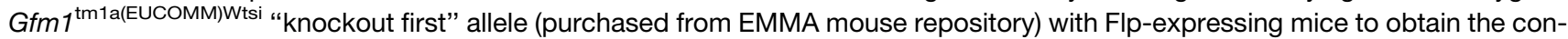
ditional allele (Skarnes et al., 2011). T-Gfm1 1 were generated by crossing Cd4Cre ${ }^{\text {ERT2/WT }}$ (Sledzińska et al., 2013) to Gfm $1^{\text {flox/flox }}$. Sex- and age-matched mice between 7 and 20 weeks of age were used for all experiments. All mice were bred and maintained under specific pathogen-free conditions at the animal facility of the Helmholtz Center for Infection Research (HZI, Braunschweig, Germany) or TWINCORE (Hannover, Germany). All animal experiments were performed in compliance with the German animal protection law (TierSchG BGBI. I S. 1105; 25.05.1998) and were approved by the Lower Saxony Committee on the Ethics of Animal Experiments as well as the responsible state office (Lower Saxony State Office of Consumer Protection and Food Safety under the permit number 33.9-42502-04-12/0839).

\section{Mouse T cell cultures}

$\mathrm{CD}^{+}{ }^{+} \mathrm{CD}_{25}{ }^{-} \mathrm{T}$ cells were isolated ex vivo from spleens and lymph nodes of mice by enrichment with EasyStep ${ }^{\mathrm{TM}} \mathrm{Mouse}^{\mathrm{CD}} 4^{+}$Isolation Kit (Stemcell Technologies) in combination with a biotin-conjugated antibody against CD25, followed by immunomagnetic negative isolation. The purity of the isolated cells was $\sim 90 \%$. RPMI 1640 GlutaMAX ${ }^{\mathrm{TM}}$ medium or IMDM GlutaMAX ${ }^{\mathrm{TM}}$ medium (both from Life Technologies) was used for Th1, Th2, and Treg or Th17 cell cultures, respectively. The medium was supplemented with $10 \%$ heat-inactivated FCS (Biochrom), $500 \mathrm{U}$ penicillin-streptomycin (PAA laboratories), and $50 \mathrm{mM} \beta$-mercaptoethanol (Life Technolo-

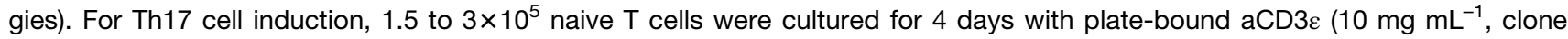
145-2C11; Bio X Cell), aCD28 (1 mg mL ${ }^{-1}$, clone 37.51; Bio X Cell), alFN-g (5 mg mL ${ }^{-1}$, clone XMG1.2; Bio X Cell), alL-4 (5 mg $\mathrm{mL}^{-1}$, clone 11B11; Bio X Cell), rhTGF- $\beta 1$ (2 ng mL ${ }^{-1}$; Peprotech), rmlL-6 (7.5 ng mL ${ }^{-1}$; Peprotech), and rmlL-1b (50 ng mL ${ }^{-1}$; Peprotech). For Th1 induction, $1 \times 10^{5}$ naive T cells were cultured for 4 days in the presence of plate-bound aCD3 $\varepsilon\left(10 \mathrm{mg} \mathrm{mL}^{-1}\right)$, aCD28 $\left(1 \mathrm{mg} \mathrm{mL}^{-1}\right)$, rmlL-12 $\left(50 \mathrm{ng} \mathrm{mL}^{-1}\right)$, and alL-4 $\left(5 \mathrm{mg} \mathrm{mL}^{-1}\right)$. For Th2 induction $1 \times 10^{5}$ naive T cells were cultured for 4 days with platebound aCD3ع (10 mg mL ${ }^{-1}$, clone 145-2C11; Bio X Cell), and aCD28 (10 mg mL $\mathrm{mL}^{-1}$, clone 37.51; Bio X Cell), alFN- $\gamma\left(10 \mathrm{mg} \mathrm{mL}^{-1}\right.$, clone

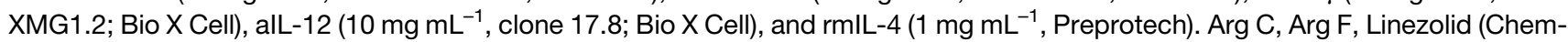
Impex), Tigecycline hydrate (Sigma), or Thiamphenicol (Chem-Impex) were added at the indicated concentrations at the onset of the culture. For proliferation analysis, naive T cells were labeled using $5 \mu \mathrm{M}$ CellTrace ${ }^{\mathrm{TM}}$ Violet Cell Proliferation Kit (Life Technologies) after magnetic sorting.

\section{Human T cell cultures}

Human cord blood samples were obtained from the Department of Prenatal Medicine and Midwifery of the Medical School Hannover $(\mathrm{MHH})$. All work with human blood samples was approved by the local ethics committee and informed consent was obtained from all subjects. After Ficoll (Biocoll) gradient, naive CD44 ${ }^{+}$T cells were enriched by magnetic separation using the EasySep ${ }^{\mathrm{TM}}$ Human Naive $\mathrm{CD}^{+} \mathrm{T}$ Cell Isolation Kit (Stemcell Technologies). $5 \times 10^{4} \mathrm{~T}$ cells were cultured for 6 days in the presence of plate-bound aCD3 $\varepsilon$ ( $5 \mathrm{mg}$ $\mathrm{mL}^{-1}$ ), in X-Vivo 15 medium (Lonza), supplemented with $2 \%$ heat-inactivated FCS (Biochrom), $500 \mathrm{U}$ penicillin-streptomycin (PAA laboratories), and $50 \mathrm{mM} \beta$-mercaptoethanol (Life Technologies). To polarize the cells towards a Th17 cell phenotype, the medium was supplemented further with rhlL-1 $\beta$ (10 ng mL ${ }^{-1}$, R\&D Systems), rhlL-23 (20 ng mL ${ }^{-1}$, R\&D Systems), rhlL-6 (20 ng mL $\mathrm{mL}^{-1}$; Peprotech), rhlL-21 (20 ng mL ${ }^{-1}$; Peprotech), rhTGF- $\beta 1$ (3 $\mathrm{ng} \mathrm{mL}^{-1}$; Peprotech), aCD28 (500 ng mL ${ }^{-1}$ ), and $20 \mathrm{mM} \mathrm{NaCl}$. Arg C and Linezolid were added at the indicated concentrations from day 0 .

\section{Naive T cell maintenance and Gfm1 deletion}

Naive T cells (CD4 ${ }^{+}$CD25 ${ }^{-} \mathrm{CD}_{2} \mathrm{~L}^{+}$CD44 $\left.{ }^{\text {low }}\right)$ were sorted from spleens and lymph nodes of mice and maintained in RPMI 1640 GlutaMAX ${ }^{\text {TM }}$ medium (from Life Technologies) supplemented with 10\% heat-inactivated FCS (Biochrom), 1X Antibiotic Antimycotic Solution (Sigma), and $50 \mathrm{mM} \beta$-mercaptoethanol (Life Technologies), containing rmlL-7 (20 ng mL ${ }^{-1}$, Peprotech). $\mathrm{rmlL}^{-7}$ (10 ng mL ${ }^{-1}$ ) was re-added at the $3^{\text {rd }}, 5^{\text {th }}, 7^{\text {th }}, 9^{\text {th }}$, and $11^{\text {th }}$ days of culture. To induce tamoxifen-mediated deletion in vitro, (Z)-4-Hydroxytamoxifen (Sigma) at $300 \mathrm{nM}$ was added at the beginning of the culture. After 12 days, naive T cells were harvested, counted, and re-plated at a density of $1.5 \times 10^{5}$ cells per well under Th17 cell-polarizing conditions as described above.

\section{Experimental autoimmune encephalomyelitis}

EAE was induced by subcutaneous immunization with $200 \mathrm{mg} \mathrm{MOG}_{35-55}$ peptide (HZI, Braunschweig) emulsified in CFA (Sigma-Aldrich), followed by intravenous injection of 200 ng pertussis toxin (Sigma-Aldrich) on days 0 and 2. To quantify disease severity, scores were assigned daily on a scale of 0-5 as follows: 0- no paralysis, 1- limp tail, 2- limp tail and partial hind leg paralysis, 3- complete hind leg paralysis, 4- tetraparesis and 5- moribund or dead. Animals were euthanized if score reached grade 3.5 for two 
consecutive days and subsequently scored as 5 the following days. To determine CNS infiltrates, mice were sacrificed at day 15 or 16 post-induction and cell suspensions from brain and spinal cord were prepared, as described previously (Berod et al., 2011). Single suspension of cells were cultured in 48-well plates in the presence of $30 \mathrm{mg} \mathrm{mL}^{-1} \mathrm{MOG}_{35-55}$ for $2 \mathrm{~h}$ followed by addition of Brefeldin $\mathrm{A}$ (5 mg mL ${ }^{-1}$; Affymetrix/eBioscience) for $4 \mathrm{~h}$. Finally, cells were analyzed by flow cytometry for expression of surface markers and cytokine production. Where indicated, Linezolid or Vancomycin were administered daily after day 3 post-induction by oral gavage (4 mg per mouse). Additionally, mice had ad libidum access to drinking water supplemented with $1 \mathrm{mg} \mathrm{mL}^{-1}$ of the indicated antibiotic. For COX1 analysis, mice were sacrificed at day 10 post-induction and splenocytes were stained for the markers of interest. For BrdU incorporation, mice were given $1 \mathrm{mg}$ of BrdU daily (days 9, 10, and 11 post-induction), sacrificed at day 12 post-induction and splenocytes were stained for the markers of interest. For in vivo deletion of Gfm1 during EAE induction, mice were administered with two doses of $2 \mathrm{mg}$ of Tamoxifen (Santa Cruz) dissolved in corn oil intraperitoneally, 3 and 5 days after EAE induction.

\section{METHOD DETAILS}

\section{Flow cytometry}

Monoclonal antibodies against the following mouse antigens were purchased from Affymetrix/eBioscience: CD4 (GK1.5), IL-17A (eBio17B7), IL-13 (eBio13A), IFN- $\gamma$ (XMG1.2), T-bet (eBio4B10), ROR $\gamma$ t (B2D), GATA-3 (TWAJ), FoxP3 (FJK-16s), CD154 (MR1). COX1 AF488 was purchased from Abcam. For human cells, the following antibodies purchased from Affymetrix/eBioscience were used: CD4 (SK3), IL-17A (eBio64DEC17). For analysis of surface markers, cells were stained in PBS containing $0.25 \%$ bovine serum albumin (BSA) and $0.02 \%$ azide. Dead cells were excluded by LIVE/DEAD ${ }^{\circ}$ Fixable Dead Cell Stain Kit (Life Technologies). For mouse intracellular cytokine staining, cells were stimulated with phorbol 12-myristate 13-acetate (PMA) $\left(0.1 \mathrm{mg} \mathrm{mL}^{-1}\right.$; Sigma-Aldrich) and ionomycin ( $1 \mathrm{mg} \mathrm{mL}^{-1}$; Sigma-Aldrich) for $2 \mathrm{~h}$ followed by brefeldin $\mathrm{A}\left(5 \mathrm{mg} \mathrm{mL}^{-1}\right)$ for $2 \mathrm{~h}$ and fixed using $2 \%$ PFA fixation followed by permeabilization with PBS containing $0.25 \%$ BSA, and $0.5 \%$ of saponin. Human intracellular staining was done as described above, but brefeldin A was added simultaneously with PMA and ionomycin instead. For transcription factor staining, cells were instead fixed with Foxp3/Transcription Factor Fixation/Permeabilization Kit (Affymetrix/eBioscience) according to manufacturer's instructions prior to permeabilization. Stained cells were acquired on a CyAn ${ }^{\mathrm{TM}}$ ADP (Beckman Coulter) or an LSR II (Becton Dickinson) and data was analyzed with FlowJo software (Tree Star, Inc.).

\section{Western blot}

Whole-cell lysates were prepared using lysis buffer (Pierce ${ }^{\mathrm{TM}}$ RIPA buffer, Thermo Scientific) supplemented with complete EASYpack Mini Protease Inhibitor Cocktail and PhosSTOP Phosphatase Inhibitor (both from Roche Applied Science). Cell lysates were separated by SDS-gel electrophoresis and transferred to PVDF membranes (Merck Millipore). Immunoblotting was performed using the following antibodies from Cell signaling: mouse anti- $\beta$-actin, goat-anti-rabbit (Horseradish peroxidase-conjugated), and anti-mouse (Horseradish peroxidase-conjugated). The following antibodies were purchased from Abcam: mouse anti-Sdha, rabbit anti-ND1, and mouse anti-COX1. Rabbit anti-AMPK $\alpha$ (23A3) and rabbit anti-phospho-AMPK $\alpha$ (Thr172) were purchased from Cell Signaling Technology, and rabbit anti-HIF-1 $\alpha$ was from Novus biological.

\section{Metabolism analysis}

Naive CD4 ${ }^{+} \mathrm{T}$ cells were plated at a density of $1 \times 10^{5}$ cells per well under Th17 cell-polarizing conditions containing the indicated drug, harvested after $72 \mathrm{~h}$ of culture and plated on 96-well XF cell culture microplates in XF assay medium (pH 7.4, both from Agilent) supplemented with D-glucose $(20 \mathrm{mM})$, and L-glutamine $(2 \mathrm{mM}, \mathrm{Gibco})$ with a density of $3 \times 10^{5}$ cells per well. Microplates were incubated for $30 \mathrm{~min}$ at $37^{\circ} \mathrm{C}$ in a non- $\mathrm{CO}_{2}$ incubator and subjected to real-time analysis of OCR using an XF96 Extracellular Flux Analyzer (Agilent). For the mitochondrial stress assay analysis, the XF Mitochondrial Stress Test was performed according to manufacturer's instructions, using subsequent injections of FCCP $(0.8 \mathrm{mM})$, oligomycin $(1 \mathrm{mM})$, and rotenone and antimycin $\mathrm{A}(0.5 \mathrm{mM})$.

Mitochondrial membrane potential measurement

Cells were stained at the indicated time points with tetramethylrodamine, ethyl ester (TMRE, Abcam ${ }^{\circ}$ ) according to the manufacturer's instructions. After a 20 min incubation with TMRE at $37^{\circ} \mathrm{C}$, cells were washed and TMRE was detected by flow cytometry.

\section{Lactate measurement}

Lactate concentration in the extracellular medium of T cells cultured under Th17 cell-polarizing conditions for $96 \mathrm{~h}$ was performed using the Lactate Assay kit from Sigma-Aldrich according to manufacturer's instructions.

NAD ${ }^{+} / \mathrm{NADH}$ ratio measurement

$\mathrm{NAD}^{+} / \mathrm{NADH}$ ratio were measured in T cells cultured under Th17 cell-polarizing conditions for 24, 48, and 96 h using NAD/NADH$\mathrm{Glo}^{\mathrm{TM}}$ Assay (Promega) according to the manufacturer's instructions.

ADP/ATP ratio measurement

The ratio of ADP to ATP were measured in T cells cultured under Th17 cell-polarizing conditions for $96 \mathrm{~h}$ using the ADP/ATP Ratio Assay kit (Abnova) according to the manufacturer's instructions. 
Mitochondrial translation assay

EL-4 cells were treated for $1 \mathrm{~h}$ with the indicated compounds or vehicle and starved for 20 min before cytosolic translation blocking.

$\left[{ }^{35} \mathrm{~S}\right]$-Methionine was added to the culture and incubated for $1 \mathrm{~h}$. Cells were subsequently harvested, lysed, and subjected to electrophoretic separation in an SDS-gel. Mitochondrial translation products were detected by autoradiography.

Electron microscopy analysis

Samples were incubated in fixative (2\% paraformaldehyde (PFA, EMS), $2.5 \%$ glutaraldehyde (GA, EMS) in $0.1 \mathrm{M}$ Sodium Cacodylate (EMS) buffer, $\mathrm{pH} 7.4$ ) at RT for 30 min. Fixative was removed by washing $5 \times 3$ min in $0.1 \mathrm{M}$ cacodylate buffer. $100 \mu \mathrm{L}$ of cell suspension was embedded by centrifugation ( $5 \mathrm{~min}$ at $1230 \mathrm{~g}$ at $30^{\circ} \mathrm{C}$ ) in $100 \mu \mathrm{L} 2 \%$ Low Melting Agarose (LMA, Gibco BRL) in $0.1 \mathrm{M}$ cacodylate buffer. Samples were then incubated in $2 \%$ osmium tetroxide (OsO4, EMS), $1.5 \%$ potassium ferricyanide (EMS) in $0.1 \mathrm{M}$ cacodylate buffer for 60 min at RT. After washing in $\mathrm{H}_{2} \mathrm{O}$, samples were incubated in $1 \%$ Thiocarbohydrazide (TCH, EMS) in water for $20 \mathrm{~min}$. TCH was removed by washing $5 \times 3 \mathrm{~min}$ in water. Then, a second incubation in OsO4 $\left(2 \% \mathrm{OsO}_{4}\right.$ in $\left.\mathrm{H}_{2} \mathrm{O}\right)$ for $30 \mathrm{~min}$ at $\mathrm{RT}$. After washing in $\mathrm{H}_{2} \mathrm{O}$ for $5 \times 3 \mathrm{~min}$, samples were incubated overnight at $4^{\circ} \mathrm{C}$ in Uranyl Acetate Replacement $\left(\mathrm{UA}\right.$, EMS) in $\mathrm{H}_{2} \mathrm{O}(1: 3)$. The next day, UAR was removed by washing in $\mathrm{H}_{2} \mathrm{O}$ for $5 \times 3 \mathrm{~min}$. The cells were then incubated for 30 min in Walton's lead solution at $60^{\circ} \mathrm{C}$. After the washing steps, the samples were dehydrated with $\mathrm{EtOH}(70 \%, 90 \%$, and $2 \times 100 \%)$, for 5 min each, followed by $2 \times$ 10 min of propylene oxide (Aldrich). Subsequent infiltration with resin (Spurr, EMS) was done by incubating in 50\% resin in propylene oxide for $2 \mathrm{~h}$, followed by at least 3 changes of fresh $100 \%$ resin (including one overnight incubation). Next, samples were embedded in fresh resin and cured in the oven at $65^{\circ} \mathrm{C}$ for $72 \mathrm{~h}$. For FIB-SEM imaging, embedded cells were mounted on aluminium SEM stubs (diameter $12 \mathrm{~mm}$ ) and samples were coated with $\sim 8 \mathrm{~nm}$ of Platinum (Quorum Q150T ES). FIB-SEM imaging was performed using a Zeiss Crossbeam 540 system with Atlas 5 software. The Focussed lon Beam (FIB) was set to remove 5 nm sections by propelling Gallium ions at the surface. Imaging was done at $1.5 \mathrm{kV}$ using an ESB (back-scattered electron) detector.

\section{QUANTIFICATION AND STATISTICAL ANALYSIS}

RNA-seq dataset, quality control, and analysis

The Raw FASTQ files were quality controlled, trimmed, and mapped to the Mus musculus reference genome (GRCm38.p5) using the RNA-seq Analysis workflow of QIAGEN's CLC Genomics Workbench 8. Expression was estimated as RPKM (Reads Per Kilobase of exon model per Million mapped reads) (Mortazavi et al., 2008). Exploratory analysis revealed gene expression patterns following treatment of naive T cells labelled with CellTrace ${ }^{\mathrm{TM}}$ Violet Cell Proliferation Kit and cultured with DMSO, Linezolid, and Arg C for 96h. Total RNA was isolated using RNeasy Micro Kit (Qiagen) according to the manufacturer's instructions. Before RNA isolation, live $\mathrm{CD}^{+}$cells which proliferated at least once were sorted from each individual proliferation cycle; cells which had not proliferated were not included in downstream analyses. Differential expression analysis was performed between the treatment groups. The statistical significance threshold level of 0.05 with Bonferroni corrected FDR p value and absolute fold change of 2 was used as a cutoff for differentially expressed genes. We compared the number of overlapping differentially expressed genes from the three treatment groups at each time points using a proportional Venn-diagram plotted using the Python matplotlib_venn library. Heatmap visualization for expression dynamics for the selected genes were plotted using the ComplexHeatmap R package. Pathway analysis was performed by uploading the processed RNA-seq data to Ingenuity Pathway Analysis (IPA, QIAGEN).

\section{Statistical analysis}

Data analysis was performed using GraphPad Prism Software. Unless otherwise stated, data were compared with a one-way ANOVA with Bonferroni multiple comparisons test. Means are given as \pm standard deviation (SD) or, where indicated, as \pm standard error of the mean (SEM). Significance was determined as follows: ${ }^{*} p<0.05 ;{ }^{* *} p<0.01$, and ${ }^{* * *} p<0.001$. When appropriate, the values for different treatments were matched and corrected with the Geisser-Greenhouse method. If values were \pm 3 SDs (or more) away from the mean, they were considered as outliers and removed from the dataset. 